\title{
Scientific basis of
} nanotechnology, implications for the food sector and \section{future trends}

M. Rossi ${ }^{a}{ }^{a, b}, *$ F. Cubaddac, L. Dini ${ }^{\mathrm{d}}$, M.L. Terranova ${ }^{\mathrm{e}}$, F. Aureli ${ }^{\mathrm{C}}, \mathrm{A}$. Sorbo ${ }^{\mathrm{f}}$ and D. Passeri ${ }^{\mathrm{a}}$

a Department of Basic and Applied Sciences for Engineering, Sapienza University of Rome, Via A. Scarpa 16, 00161 Rome, Italy

${ }^{b}$ Centro di Ricerca per le Nanotecnologie Applicate all'Ingegneria della Sapienza (CNIS), Sapienza University of Rome, Piazzale A. Moro 5, 00185 Rome, Italy (Department of Basic and Applied Sciences for Engineering, Sapienza University of Rome,

Via A. Scarpa 16, 00161 Rome, Italy. Tel.: + 3906 49766341; fax: + 3906 44240183; e-mails: marcorossi@uniroma1.it; marco.rossi@nanoshare.com)

'Department of Food Safety and Veterinary Public Health, Istituto Superiore di Sanità - National Health Institute, Viale Regina Elena 299, 00161 Rome, Italy ${ }^{\mathrm{d}}$ Department of Biological and Environmental Science and Technology, University of Salento,

Prov.le Lecce-Monteroni, 73100 Lecce, Italy

eDepartment of Chemical Sciences and Technologies - MinimaLab, University of Rome Tor Vergata, Via Della Ricerca Scientifica, 00133 Rome, Italy fEuropean Union Reference Laboratory for Chemical Elements in Food of Animal Origin (EURL-CEFAO) -

Department of Food Safety and Veterinary Public Health, Istituto Superiore di Sanità - National Health Institute, Viale Regina Elena 299, 00161 Rome, Italy

* Corresponding author.
Nanotechnologies are opening up new horizons in almost all scientific and technological fields. Among these, applications of nanotechnologies are expected to bring large benefits and add value to the food and food-related industries through the whole food chain, from production to processing, safety, packaging, transportation, storage and delivery. Nanotechnology consists in the realization and manipulation of nano-sized matter, the unique properties of which with respect to their bulk counterparts are illustrated and discussed. Then, the main tools and techniques routinely used in nanotechnology for the nanoscale characterization of food matrices as well as for the analytical determination of nanomaterials in food samples are reviewed. Finally, safety and risk assessment issues are discussed and an overview of applications of nanotechnology to the food sector is provided along with a description of the current regulatory framework.

\section{Introduction}

Nanosciences and nanotechnologies connect diverse disciplines, among others physics, chemistry, life sciences, medicine, cognitive sciences, engineering, information and communication technologies, and therefore represent a real convergence among up-to-now distant fields of knowledge. Perhaps all the scientific and technological fields have taken, are taking, and/or have the possibility to take advantage of nanotechnology. Among these, the impact of nanoscience in many fields connected to health and well-being is nowadays very strong and the applications of nanotechnologies are expected to bring large benefits to the food and nutrition sector. Nanotechnologies may provide new ways and tools for controlling properties and structuring foods, introducing new features and creating added value. The phenomena that take place at the nanometer scale offer lots of opportunities for innovation that have the potential to impact substantially the food industry worldwide, as nanotechnologies can be applied to the whole food chain, from production to processing, safety, packaging, transportation, storage and delivery (Cushen, Kerry, Morris, Cruz-Romero, \& Cummins, 2012; Silvestre, Duraccio, \& Cimmino, 2011; Weiss, Takhistov, \& McClements, 2006). The impacts of and needs for nanotechnological applications in food and related sectors are depicted in Fig. 1. The potential applications of nanotechnologies to food-related fields are nearly endless and the design and production of 


\section{Abbreviations}

AAS Atomic absorption spectroscopy

AES Atomic emission spectroscopy

AEM Analytical electron microscopy (a combination of analytical tools, such as spectroscopy, and electron microscopy for composition analysis)

AFM Atomic force microscopy

ANUC Analytical ultracentrifugation

ASEM Atmospheric scanning electron microscopy

BET Brunauer Emmett Teller method

CE Capillary electrophoresis

CFM Chemical force microscopy

CLSM Confocal laser scanning microscopy

CNT Carbon nanotube

DLS Dynamic light scattering

DMA Differential mobility analysis

ED Electron diffraction

EDX Energy dispersive X-ray spectroscopy

EFLM epifluorescence light microscopy

EM electron microscopy

ENM Engineered nanomaterial

ESEM Environmental scanning electron microscopy

FCM Food contact material

FFF Field flow fractionation

FT-IR Fourier transform infrared spectroscopy

GC-MS Gas chromatography-mass spectrometry

HDC Hydrodynamic chromatography

HPLC High performance liquid chromatography

ICP-MS Inductively coupled plasma mass spectrometry

IMS Ion mobility spectrometry

LDE Laser doppler electrophoresis

LM light microscopy

MALDI-ToF-MS Matrix-assisted laser desorption/ ionization-time of flight mass spectrometry

MALS Multi-angle light scattering

MS Mass spectrometry

NMR Nuclear magnetic resonance spectroscopy

NP Nanoparticle

NTA Nanoparticle tracking analysis

PCS Photo correlation spectroscopy

QqQ Triple quadrupole mass spectrometer

SAS Synthetic amorphous silica

SAXS Small-angle X-ray scattering

SEC Size exclusion chromatography

SEM Scanning electron microscopy

SLS Static light scattering

SMPS Scanning mobility particle sizing

SNOM Scanning near-field optical microscopy

sp-ICP-MS Single particle inductively coupled plasma mass spectrometry

STEM Scanning transmission electron microscopy
SThM Scanning thermal microscopy

STM Scanning tunneling microscopy

STXM Scanning transmission X-ray microscopy

SWCNT Single walled carbon nanotube

TEM Transmission electron microscopy

UNCD Ultrananocrystalline diamond

XPS X-ray photoelectron spectroscopy

XRD X-ray diffraction

ENMs, nano-based structures, devices and systems provide new ways of producing and processing food as well as protecting safety and authenticity of food products in the supply chain. The increasing interest in nanotechnology applied to the food sector is demonstrated by the increasing number of scientific publications per year retrieved using a database of peer-reviewed literature (Scopus) and searching for 'nanotechnology' and 'food' in the title, abstract and keywords (Fig. 2). The output likely underestimates the number of academic journal articles dealing with applications of nanotechnologies to food and related sectors.

Despite the projected benefits, this exciting technological frontier is raising regulatory issues and public concern regarding safety and environmental effects. For regulatory purposes, various countries have adopted different and sometimes diverging approaches (Cushen et al., 2012; Tinkle et al., 2014). As to public perception, the critical point is a widespread sentiment that nanoscale processes and products, interfering with the physiology of living species and with the environmental processes, could expose the humankind and the environment to unforeseen risks. This anxiety, rather common among the general public, could represent the stumbling block able to stop the advancement of nanotechnologies in a number of application fields, including the food sector.

In order to fill the knowledge gaps on the environmental fate of ENMs, the investigation of life cycle of ENMs, to determine how long they survive, how they distribute and if and how they finally degrade, has been the first task pursued by environmental scientists. A series of researches carried out in the frame of national and international initiatives are currently evaluating the risks connected to the use of the various ENMs.

The other main issue is the consumer-safety implications from nanotechnology applications. Physicochemical properties of ENMs are important for new applications, but are also extremely relevant in terms of potential risks for human health. A better understanding of the properties, behavior and effects of ENMs is the subject of many research efforts that encompass diverse disciplines, from imaging and analytical science to nanotoxicology. 


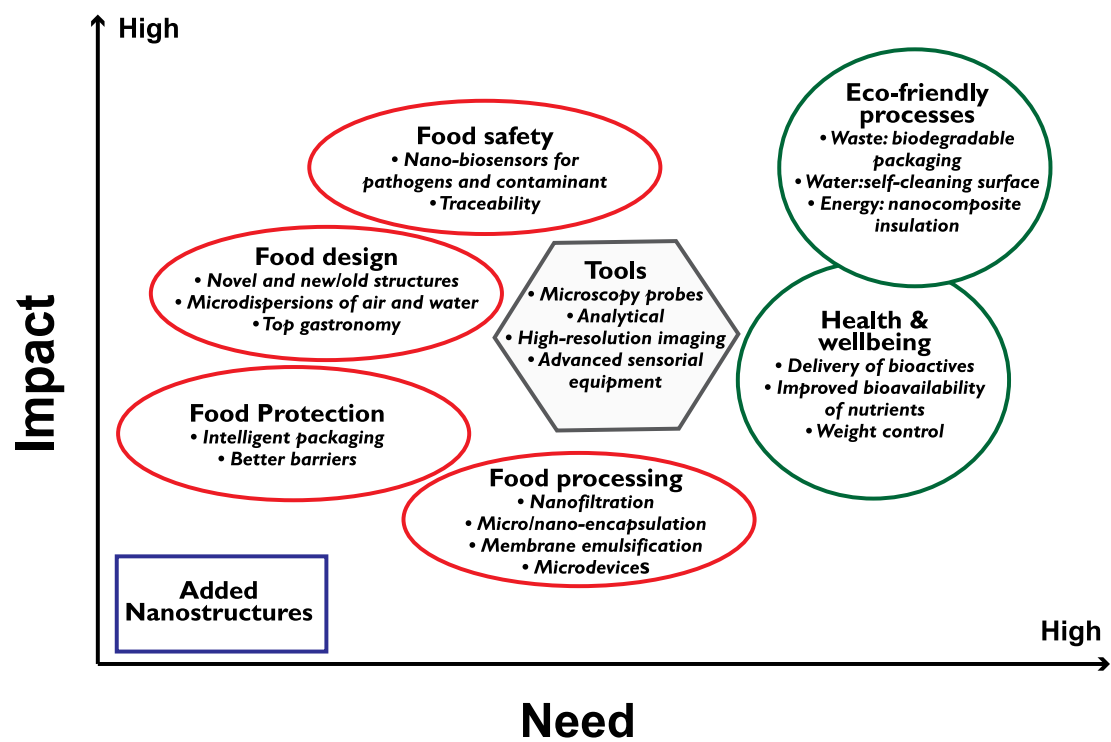

Fig. 1. Impacts and needs of nanotechnological applications in foods and food processing.

As the comprehensive presentation of the world of nanotechnologies would far exceed the scope of the present review, hereafter we illustrate the physical basis of the different properties of the ENMs compared to the corresponding bulk counterparts. The safety and risk assessment issues and the challenges of the characterization and analytical determination of ENMs in complex matrices such as food will be then dealt with and state of the art of imaging and analytical techniques will be presented. Finally, an overview is given of the applications on nanotechnologies in food and related sectors and the current regulatory framework.

\section{Nanotechnology and nanomaterials}

Properties of nanomaterials

The term nanotechnology refers to the conscious synthesis, manipulation, assembly and use of nano-sized objects

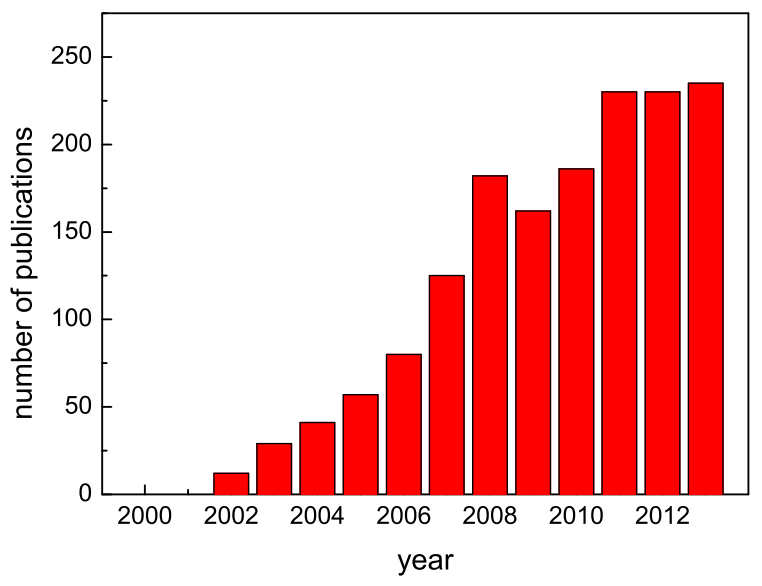

Fig. 2. Statistics of the number of publications per year retrieved using a database of peer-reviewed literature (Scopus), searching for 'nanotechnology' and 'food' in the title, abstract and keywords. to fabricate novel materials, structures and devices with properties tailored to specific scientific and technological purposes. Indeed, a great variety of ENMs can be synthesized, manipulated, combined, to obtain a virtually endless number of materials and structures with novel physical or chemical properties (Fig. 3). A quick glance at the constantly increasing number of ENMs, at the variety of obtained properties and at the foreseen possible applications reported in literature is undoubtedly exciting for scientists and seems to suggest that their only limit is imagination ('Theres plenty of room at the bottom', quoting R. P. Feynman).

Since ancient times different methodologies have been developed and optimized empirically to produce handicrafts (e.g., blades, pottery, glasses) with amazing physical (e.g., mechanical or optical) properties. After investigation with modern characterization techniques, such properties have been ascribed to the presence of nanomaterials produced by the manufacturing processes. For example, by analyzing a genuine Damascus sabre dating back to the seventeenth century, carbon nanotubes and cementite nanowires have been found in Damascus steel which is known to possess extraordinary mechanical properties (Reibold et al., 2006). Colloidal gold NPs have been recognized as the origin of the reddish color of dyes used as colorant to obtain ruby glasses and ceramics (Daniel \& Astruc, 2004; Sharma, Park, \& Srinivasarao, 2009), such as the 'Purple of Cassius', the preparation of which using gold and tin dioxide has been reported in the seventeenth century (Hunt, 1976). Also, the presence of gold NPs is responsible for the color of some ancient glass handiworks, the most famous being probably the Lycurgus cup (dating back to the fifth century B.C.), which appears green or red in reflection or transmission, respectively (Barber \& Freestone, 1990; Wagner et al., 2000). 


\begin{tabular}{|c|c|}
\hline Particle type and shape & Description \\
\hline \multicolumn{2}{|l|}{ 'Solid' nanoparticles } \\
\hline & $\begin{array}{l}\text { Soherical or compact particles } \\
\text { compositionally homogeneous }\end{array}$ \\
\hline & $\begin{array}{l}\text { Nanofiber } \\
\text { compositionally homogeneous }\end{array}$ \\
\hline & $\begin{array}{l}\text { Nanotube } \\
\text { compositionally homogeneous }\end{array}$ \\
\hline & $\begin{array}{l}\text { Nanoplate } \\
\text { compositionally homogeneous }\end{array}$ \\
\hline & $\begin{array}{l}\text { Complex non-spherical particles } \\
\text { compositionally homogeneous }\end{array}$ \\
\hline & $\begin{array}{l}\text { Compositionally heterogeneous particles } \\
\text { compositional variation core vs. surface }\end{array}$ \\
\hline & $\begin{array}{l}\text { Compositionally heterogeneous particles. } \\
\text { distributed compositional variation }\end{array}$ \\
\hline 6800 & $\begin{array}{l}\text { Homogeneous aggregates/agglomerates } \\
\text { consisting of a single particle class }\end{array}$ \\
\hline & $\begin{array}{l}\text { Heterogeneous aggregates/agglomerates } \\
\text { consisting of diverse particle types }\end{array}$ \\
\hline \multicolumn{2}{|c|}{ Nano delivery systems: lipid based } \\
\hline & $\begin{array}{l}\text { Nanoliposomes /archaeosomes } \\
\text { bilayer lipid vesicles }\end{array}$ \\
\hline & $\begin{array}{l}\text { Micelle } \\
\text { single layer lipid vesicles }\end{array}$ \\
\hline & $\begin{array}{l}\text { Nanocochleates } \\
\text { lipid layer sheet rolled up in spiral fashion }\end{array}$ \\
\hline \multicolumn{2}{|c|}{ Nano delivery systems: polymer based } \\
\hline & $\begin{array}{l}\text { Micelle } \\
\text { aggregated copolymers }\end{array}$ \\
\hline & $\begin{array}{l}\text { Nanosphere } \\
\text { aggregated copolymers generating a solid central core }\end{array}$ \\
\hline & $\begin{array}{l}\text { Nanocapsule /Polymersome } \\
\text { polymer membrane surrounding a central cavity: } \\
\text { - Nanocapsule: oily liquid cavity, single layer membrane } \\
\text { - Polymersome: aqueous cavity, bilayer membrane } \\
\text { (similar to nanoliposome) }\end{array}$ \\
\hline
\end{tabular}

Fig. 3. Different forms and shapes of nano-objects (adapted from Bouwmeester et al., 2009).

Nanomaterials are characterized by having at least one dimension ranging from about $1 \mathrm{~nm}$ to $100 \mathrm{~nm}$, although the upper limit of $100 \mathrm{~nm}$ is used by general consensus without any scientific evidence to support a disappearance of nano-properties above this value and some have suggested to consider nanotechnology-derived products also materials exhibiting properties or phenomena (including biological effects) that are attributable to their dimensions, even if the latter fall outside the nanoscale range, up to 1 micron (Tinkle et al., 2014). More specifically, they can be classified as: (i) 0-dimensional (OD) nanomaterials, when all the three dimensions are below $100 \mathrm{~nm}$ (e.g., NPs, quantum dots); (ii) 1-dimensional (1D) ENMs, with two dimensions below $100 \mathrm{~nm}$ (e.g., nanotubes, nanowires, 
nanorods); (iii) 2-dimensional (2D) ENMs, with only one dimension below $100 \mathrm{~nm}$ (e.g., ultrathin films); (iv) 3dimensional (3D) ENMs, which are not nanometer sized materials and are constituted by the assembly of nanometer elementary structures (e.g., materials with nanocrystalline grains, clusters of ENMs) or by ENMs filling a host matrix (e.g., nanocomposites) (Rösler, Bäker, \& Harders, 2007).

ENMs exhibit physical and chemical properties which may dramatically differ from those of the corresponding bulk materials (Lue, 2007; Roduner, 2006). Indeed, the properties of the latter are typically independent on their actual shape and dimension. Conversely, when one or more dimensions are in the nanometer range the properties of the materials change, scaling with the dimensions, mainly due to the superimposition of surface and quantum effects (Roduner, 2006).

Surface effects are produced by the increase in the surface-to-volume ratio, or equivalently in the fraction of atoms on the surface with respect to the total number $N$ of atoms in the material that is proportional to $N^{-1 / 3}$. Even in the case of perfectly crystalline bulk materials, surfaces and interfaces represent discontinuities in the periodic lattice and their atoms undergo reconstruction to saturate the missing bonds ('God made the bulk; the surface was invented by the devil', according to an aphorism attributed to W. Pauli). Owing to a low number of direct neighbors, the larger fraction of atoms on the surface, edges and corners of ENMs results in the scaling of coordination number, cohesive energy, melting point and temperature of other phase transitions, which in addition are no longer sharp (Buffat \& Borel, 1976; Roduner, 2006). Finally, the larger surface-to-volume ratio represents an advantage for the surface functionalization of ENMs compared to their bulk counterparts, which is of the utmost importance in several technological applications, e.g., drug delivery.

Quantum effects are responsible for amazing properties of ENMs constituted by metals and semiconductors. The delocalization of electron states in bulk metals and semiconductors results in a band structure and density of states that are not affected by the actual shape and dimension of the materials. Conversely, when the dimensions of such materials are reduced to the nano-range, the electron states are delocalized over the entire ENM and thus are dramatically affected by its dimensions (Roduner, 2006). Examples of size-dependent properties in metal and semiconductor NMs due to quantum effects are represented by nonmetal to metal transitions, band gap energy, ionization potentials, electron affinities, catalytic activity and selectivity (Roduner, 2006). In particular, variable band gap energy, which results in tunable absorption and fluorescence wavelengths, is the origin of the optical properties of the above mentioned dyes based on colloidal gold NPs and, more in general, of colloidal metal NMs (NPs, nanoshells, nanocages) with tunable size and shape dependent colors (T. Huang \& Xu, 2010; X. Huang \& El-Sayed, 2010). Quantum effects are responsible also for the magnetic moments observed in small NPs of nonmagnetic materials (Roduner, 2006). Finally, in NPs of ferromagnetic materials several size-dependent phenomena occur such as the transition from ferromagnetism to superparamagnetism characterized by the absence of hysteresis in the magnetization curves (Jun, Seo, \& Cheon, 2008). The magnetic coercivity depends on the dimension; equal to zero in small singledomain superparamagnetic NPs, it first increases and then decreases reaching its bulk value as the diameter increases (Jun et al., 2008). Finally, saturation magnetization is dependent on the NP size due to spin canting effects (Jun et al., 2008; Morales et al., 1999).

The par excellence example: carbon nanomaterials

The huge perspectives of nanotechnologies are, first of all, the direct consequence of the circumstance that for ENMs, not only their chemical composition but also their morphological and surface properties are crucial in determining their characteristics. Changes in the physicochemical characteristics can induce changes in chemical and physical properties, reactivity, catalytic activities and in turn alter their toxicity, fate and behavior in environmental media and toxicokinetics (Schwirn, Tietjen, \& Beer, 2014).

Carbon has long been known to exist in the two different allotropic forms of diamond and graphite, with different structures, bonding characteristics and, as a consequence, different chemical and physical properties. In 1985, the discovery of buckyballs (or fullerenes) (Kroto, Heath, O'Brien, Curl, \& Smalley, 1985) has opened entirely new perspectives about the carbon chemistry and physics, making possible the subsequent discovery of CNTs in 1991 (Iijima, 1991). The fullerenes (C60, C70, and others) are polyhedral entities formed by a monolayer of carbon atoms linked by a network of hexagons and pentagons. CNTs can be regarded as rolled-up graphene sheets of cylindrical shape with single or multiple layer walls, exhibiting outstanding properties, very different from those of bulk carbon or graphite. The dimensions of SWCNTs are typically in the range $1-2 \mathrm{~nm}$ in diameter by $0.1-1.0 \mu \mathrm{m}$ in length. CNTs can be prepared by a large variety of chemical vapor deposition (CVD) methods (Terranova, Sessa, \& Rossi, 2006) and other techniques (Tao, Endo, \& Kaneko, 2012). Some of the most relevant properties of SWCNTs compared to those of other technological materials present on the market can be easily find elsewhere (see, for instance, http://www.raymor.com/nanotech/carbonnanotubes/). These outstanding properties make SWCNTs the ideal component for the development of new technologies, with possible use in a broad variety of applications, e.g., reinforcement fibers in composite materials, additive for conductive polymers, electromagnetic shielding, battery electrodes, supercapacitors, catalyst supports, field emission devices, gas and biological sensors, filters and many other applications involving also the food sector.

Overall, we have to get used to the fact that chemical and physical properties of carbon are not related only to 
the existence of two allotropes and the same holds true for all chemical elements. When the sample is downsized to the nano-scale, the behavior of an element depends on size, shape and dimensionality. In such a context, most recently, a great attention has been reserved to graphene, basically a single layer of carbon atoms with $\mathrm{sp}^{2}$ hybridization, i.e., one atomic layer of the classical graphite, which can be considered the most amazing and versatile substance available to mankind. Graphene has been first produced in a surprising easy way in 2004 (This Month in Physics History: October 22, 2004: Discovery of Graphene, http:// www.aps.org/publications/apsnews/200910/physicshistory. cfm), starting from graphite and simply using adhesive tape. A few years later, A. Geim and K. Novoselov won the Nobel Prize in Physics in 2010 'for groundbreaking experiments regarding the two-dimensional material graphene' (The Nobel Prize in Physics 2010, http://www. nobelprize.org/nobel_prizes/physics/laureates/2010/).

Another example of the peculiar nano-properties of carbon depending significantly on size, shape and dimensionality is represented by UNCD (Shenderova \& Gruen, 2012). UNCDs are a special form of diamond particles with sizes in the range $3-5 \mathrm{~nm}$, produced by detonation or by laser ablation (Baidakova et al., 2013). This innovative material is distinguished by unique characteristics - such as its lattice structure, large surface/volume ratio - and presents unique properties that give rise to a wide area of exceptional applications. The set of outstanding attributes (Mochalin, S, Ho, \& Gogotsi, 2012) include mechanical, tribological (extremely low friction coefficient of about 0.01 ), transport (tunable electrical conductivity), electrochemical (wide working potential window), and electron emission properties (low, stable threshold field (Guglielmotti et al., 2009)). The properties of UNCD make them promising for the creation of novel materials with extraordinary functions.

The outstanding properties of carbon nanomaterials can be considered the most relevant and typical example of the potential of the nanotechnologies, inducing some to claim that the future will be an era of carbon after the current one based on iron, steel and silicon. Fig. 4 shows a selection of significant examples of the three most relevant allotropes of carbon at the nanoscale (CNTs, nanodiamonds and graphene), investigated through the use of the most used diffraction and microscopy techniques in nanoscience and nanotechnology.

The properties of the C-based ENMs mentioned above are extremely attractive for the realization of innovative polymer nanocomposites (PNCs), in which the nonpolymeric element has at least one dimension on the nanoscale (Tamburri et al., 2014; Zaman, Manshoor, Khalid, \& Araby, 2014). In the near future, PNCs with C-based NMs are expected to find application in FCMs.

\section{Safety issues and risk assessment}

Although making materials smaller can generate novel and useful properties, nanotechnology has provoked concern and debate from the perspective of safety both in the scientific community and in the public. A major issue is that there is insufficient knowledge on how altered physicochemical properties and potentially increased systemic bioavailability of ENMs may influence their toxicological properties. NPs have much larger surface areas and may exhibit substantially different physicochemical and biological properties compared to conventional substances with the same chemical composition. The promise of nanotechnology contributing to significant advances in fields as diverse as medicine, electronics, consumer products, food and nutrition must be weighed against the realization that we currently know relatively little about the potential adverse effects of ENMs on human health and the environment.

Another issue is how to approach the safety assessment of products of nanotechnology. Current toxicity-testing approaches used for conventional substances are suitable starting points for risk assessment of ENMs but they may need methodological modifications since they appear to be inadequate to detect all aspects of potential toxicity of nanosized materials. Additional endpoints presently not routinely addressed may need to be considered in addition to traditional endpoints whereas for hazard characterization the relationship of any toxicity to the various dose metrics that may be used, such as size and other physicochemical parameters of ENMs, has to be explored since mass concentration alone (as used for conventional substances) is clearly insufficient. In particular, decrease of particle size in the nanoscale has been identified as a main parameter for the increased toxicity of different materials (Bouwmeester et al., 2009).

Applications of nanotechnology to the food sector pose the issue of consumer exposure to NPs through consumption of food and beverages (Fig. 5). If particles are absorbed in the gut, there is a potential for internal systemic exposure. Once in the body, NPs with large reactive surfaces may cross biological barriers to reach those parts of the body which are otherwise protected from entry of (larger) particulate materials. The issue of potential toxicity arises especially for some insoluble and possibly biopersistent inorganic ENMs (also termed as 'hard' NMs), which may bioaccumulate in tissues.

A healthy digestive system only allows absorption of nutrients from the gastrointestinal tract after digestion of foods. The gastrointestinal wall is designed to ensure the passage of dietary nutrients and prevent the passage of larger or foreign material. In relation to nanosized food ingredients, it is known that certain food substances exist naturally, or are metabolized in the body, at a nano-scale (Chaudhry et al., 2008). Many food proteins are globular structures between tens and hundreds of nanometers in size, and most polysaccharides and lipids are linear polymers less than $2 \mathrm{~nm}$ in thickness. Processing of food ingredients and additives to make them nanosized, as some natural food components are, is likely to enhance their 

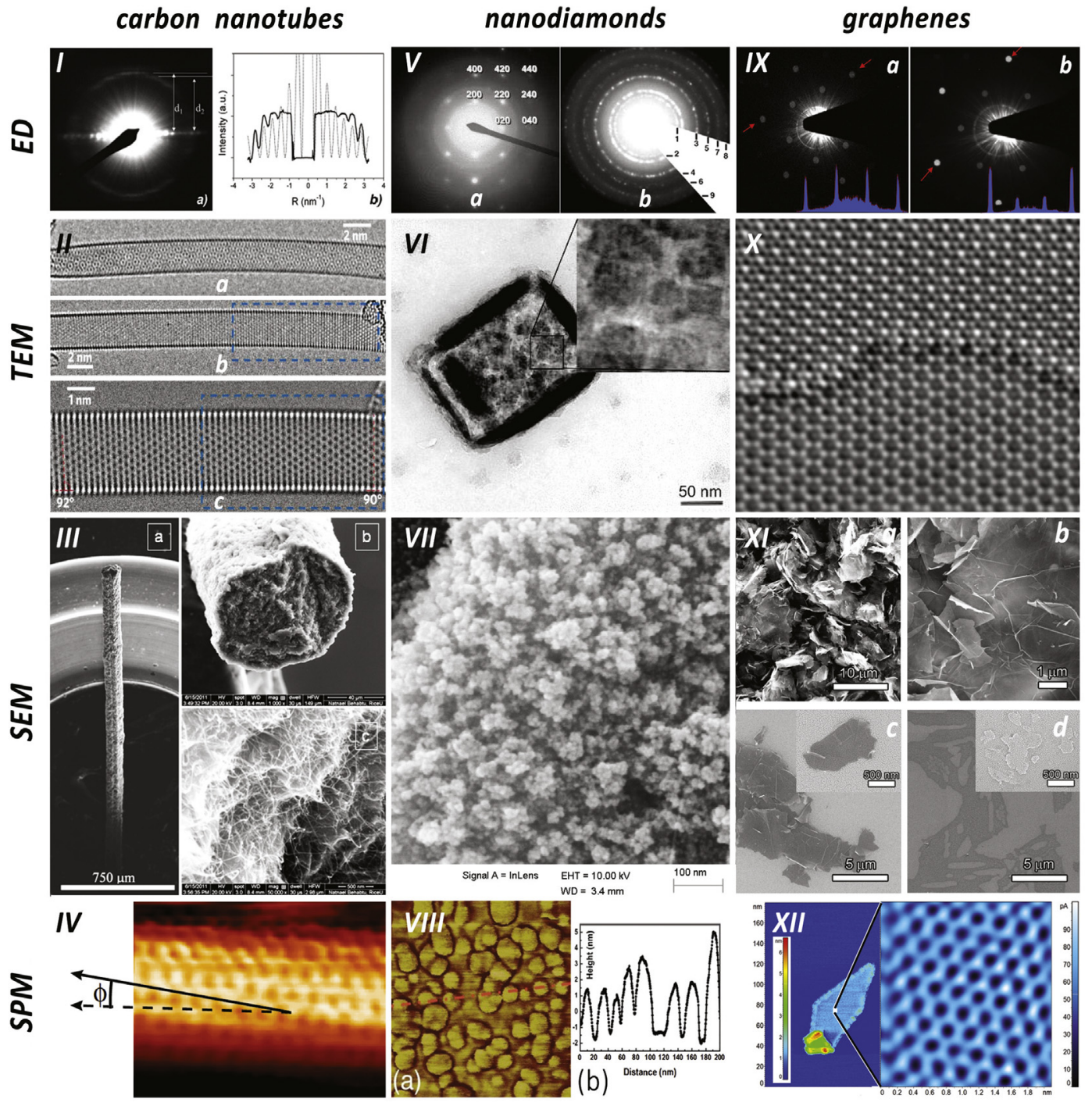

Fig. 4. Selection of significant examples of the three most relevant allotropes of carbon at the nanoscale (carbon nanotubes, nanodiamonds and graphene), investigated through the use of different Electron Diffraction (ED), Transmission Electron Microscopy (TEM), Scanning Electron Microscopy, and Scanning Probe Microscopy (SPM) techniques. (I) (a) ED pattern performed onto an isolated bundle of SWCNTs; (b) experimental equatorial line profile (solid line) of the diffraction intensity and the corresponding simulation (dotted line), for the determination of the radius (i.e., chirality) of the SWCNTs (Serra et al., 2008). (II) Low-voltage aberration-corrected High Resolution TEM is able to resolve carbon lattice structure and to determine the chirality of individual nanotubes: (a) SWCNT with chirality $(18,8)$; (b) zig-zag SWCNT with chirality $(28,0)$ suspended in free space with a bend; (c) at higher magnification showing the full atomic structure (Warner, Young, Kirkland, \& Briggs, 2011). (III) SEM images of an SWCNT fibre: (a) general view of the fibre fixed on the SEM circular holder; (b) and (c) top section view of the fibre with details (Guglielmotti et al., 2013). (IV) Atomically resolved STM image of an individual CNT. The image vertical size is $3 \mathrm{~nm}$. The dashed arrow indicates the direction of the tube axis and the solid arrow denotes the direction of the nearest neighbor hexagon rows. The angle between these two arrows is the chiral angle $\varphi$ (Venema, Wildöer, Dekker, Rinzler, \& Smalley, 1998). (V) (a) Selected Area Electron Diffraction (SAED) pattern from the shaped morphology imaged in the TEM image reported in the following panel VI. The indexing of the diffraction spots demonstrates the presence of the crystalline phase corresponding to $\mathrm{n}$-diamond (sg $F \overline{4} 3 \mathrm{~m}$ ). (b) Electron diffraction pattern taken from the disaggregated material after the interaction with the TEM e-beam (for about $60 \mathrm{~s}$ ) (Terranova et al., 2009). (VI) TEM image of a rectangular assembly (with sizes of about $150 \times 200 \mathrm{~nm}$ ) obtained by a colloidal stable dispersion of nanodiamond particles. The inset shows at higher magnification the close-packed arrangement of the diamond nanocrystals (Terranova et al., 2009). (VII) 3D networks of closely packed diamond nanograins. (VIII) a: Atomic Force Microscopy phase image of $5 \mathrm{~nm}$ nano-diamond particles dispersed on a silicon wafer (area $200 \times 200 \mathrm{~nm}$ ). The dashed line indicates the path of the line scan (b), the data being obtained from a corresponding height image (Williams et al., 2007). (IX) Diffraction patterns of (a) single layer and (b) double layer graphene. Intensity profile plots taken between the red arrows are shown in the inset. The diffraction patterns were acquired with a Tecnai F30 (Zan, Ramasse, Jalil, \& Bangert, 2013). (X) HRTEM image of single and bilayer graphene with atomic resolution (Urban, 2011). (XI) (a) and (b) Low and high magnification images of original graphene sheets. (c) Low and high (insert) magnification images of graphene sheets dispersed by ultrasonication only. (d) Low and high (insert) magnification images of graphene sheets dispersed by the coupled hydrogen passivation and ultrasonication (Y. Yang, Rigdon, Huang, \& Li, 2013). (XII) STM image of a graphene nanoplatelet on high oriented highly oriented pyrolytic graphite (HOPG) acquired in constant current mode in air and atomically resolved image obtained in constant height mode in air. 


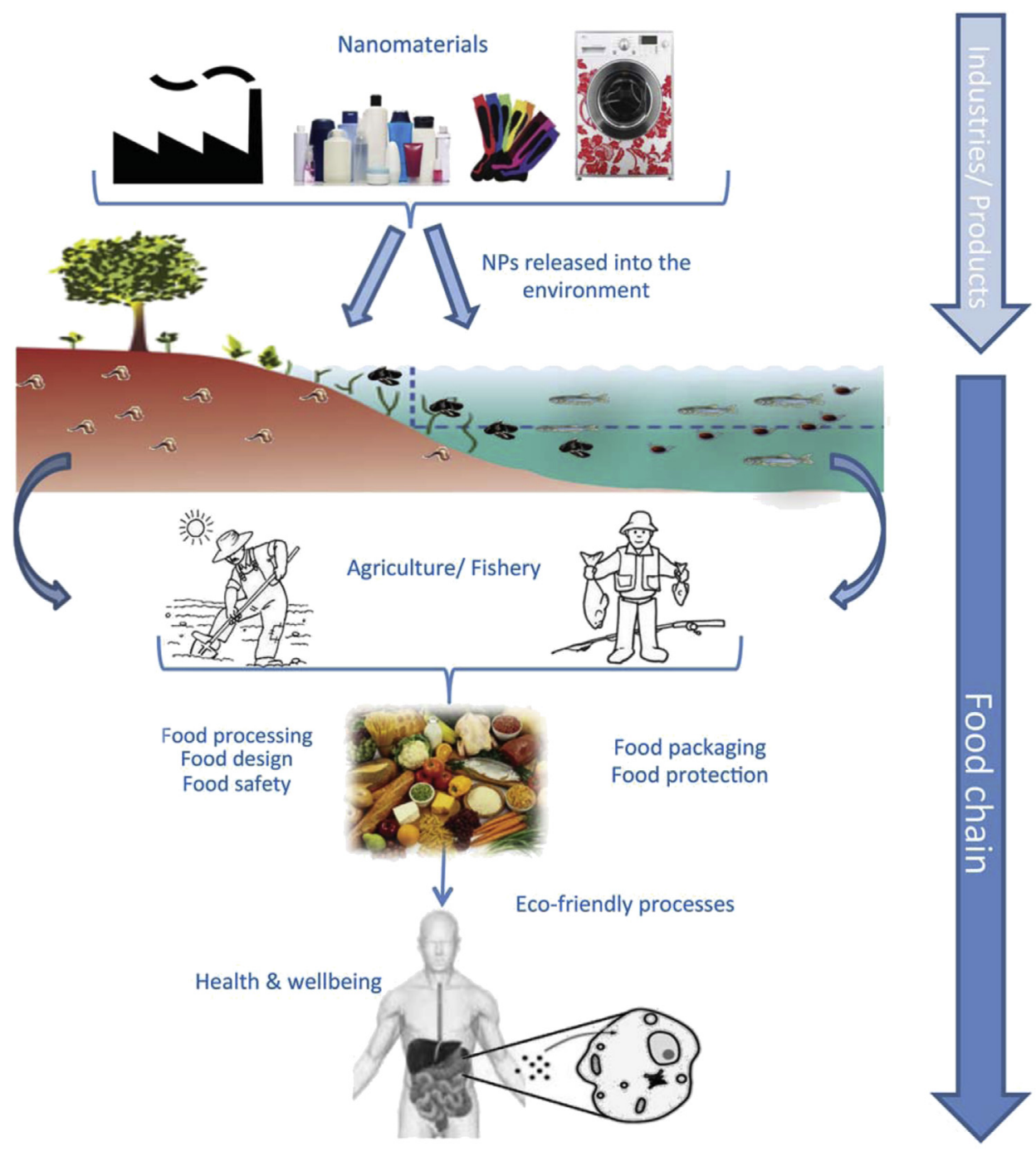

Fig. 5. Consumer exposure to NPs through consumption of nano-food. Additional dietary exposure may result from NPs released in the environment that enter the food chain.

ability to cross the gut wall and the higher absorption and bioavailability will give rise to higher internal exposure. As a consequence, a number of possible consumer health implications are envisaged to emerge from the consumption of food products containing nanosized ingredients and additives. These range from changes of nutrient profile in the body, to introduction of toxic substances or viruses adsorbed on nano-surfaces, to a variety of toxic effects at the cellular level such as increased production of oxyradicals and, consequently, oxidative damage. Some engineered NPs, such as nanosilver, are known to have strong antimicrobial activity, but at present little is known on their potential effects on the gut natural microflora.

A critical aspect influencing the biological effects on ENMs is the behavior, interactions and fate of NPs in the gastrointestinal tract. If, for instance, particles have a high dissolution rate they may completely dissolve/degrade in the gastrointestinal tract and be transformed to the nonnanoform substance, i.e., to the respective soluble (ionic or molecular) form. This, however, does not exclude possible effects of localized exposure in the gastrointestinal tract that need to be considered in safety assessment. On the other hand, NPs may undergo a variety of transformations in the gut, e.g., agglomeration, aggregation, adsorption or binding with other food components, and reactions with acid and digestive enzymes. Nanosized particles may indeed be released from the food matrix. A recent in vitro study addressing the fate of SAS in food during human digestion showed that in the intestinal digestion stage silica NPs exist even in higher amounts than in the saliva (mouth) digestion stage and that, upon consumption of foods containing SAS in the form of the food additive E551, the gut epithelium is most likely exposed to nanosized silica (R. Peters et al., 2012).

Translocation of particles through the intestinal wall is a multi-step process, involving diffusion through the mucus lining the gut wall, which is the first barrier they have to pass before entering the body, followed by contact with 
enterocytes or M-Cells of the gastrointestinal epithelium (the second barrier), by cellular or paracellular transport, and finally by post-translocation events. Particles may pass through the epithelial cells through transcytosis by enterocytes (as in normal digestion), transcytosis by M-Cells in Peyer's patches (PP), or by passive diffusion (Fröhlich \& Roblegg, 2012). Smaller particles are generally absorbed more readily and faster than larger ones so that the uptake of NPs of a given type is greater compared to respective microparticles and increases with decreasing size. Surface properties and the existence of any surface coating critically affect uptake.

When NPs pass the gastrointestinal epithelium and end up in the systemic blood circulation, they can interact with various blood-components. An important property of ENMs is interaction with proteins. In biological matrices such as food or body fluids, ENMs develop a coating of proteins or lipids (described as a 'corona'). The protein corona is not a stable association and can be altered and replaced throughout the life cycle of the ENM, dynamically changing in relation to the macromolecules and environmental conditions encountered.

Once in the systemic circulation, the ENM is rapidly distributed throughout the body, gaining access to internal body compartments with further internalization and retention in cells and organelles. Potential consequences of cellular interactions include cytotoxicity, inflammation, oxidative stress, and genotoxic effects. Of crucial importance is the potential passage of natural barriers, i.e., apart from cellular barriers, the blood-brain barrier or the placental barrier. Importantly, ENMs are taken up by the mononuclear phagocyte system (MPS) especially in spleen and liver and in order to address this from the standpoint of safety there may be a need for extended toxicokinetic studies depending on the biopersistence of the ENM. The toxicokinetic studies will provide information on the timing and extent of ENM accumulation in organs and tissues and clearance from these tissues. Availability of toxicokinetic data may for instance enable to base risk assessment of ENMs on internal concentrations, i.e., by comparing estimated organ concentration in humans exposed to the ENM via the diet with those in animal toxicity studies, which has major advantages in cases of tissue accumulation over time and dose-dependent absorption (van Kesteren et al., 2014). Some studies on the toxicology of inorganic ENMs in rodents after oral exposure are summarized in Table 1.

The European Food Safety Authority (EFSA), in the 2009 scientific opinion on the potential risks arising from nanoscience and nanotechnologies on food and feed safety, affirmed that the risk assessment paradigm (hazard identification, hazard characterization, exposure assessment and risk characterization) is applicable for ENMs (EFSA, 2009). However, since different types of ENMs - even with the same chemical composition may vary as to their toxicological properties, the risk assessment of ENMs has to be performed on a case-bycase basis. The EFSA stated that appropriate data for risk assessment of an ENM in the food and feed area include comprehensive characterization of the ENM, information on whether it is likely to be ingested in nanoform, and, if absorbed, whether it remains in nanoform at absorption. The latter is a critical point and in the subsequent guidance on how to assess the risks of ENMs in food and feed the EFSA stated that unless complete degradation/dissolution in the GI tract is demonstrated with no absorption of particles as such, hazard identification and hazard characterization should include information from in vitro genotoxicity (gene mutations in mammalian cells test, micronucleus test), ADME (absorption, distribution, metabolism and excretion) and repeated dose 90-day oral toxicity studies in rodents as well as in vivo genotoxicity (if positive in vitro or not testable in vitro) (EFSA, 2011). Overall, the risk of an ENM is determined by its chemical composition, physicochemical properties, its interactions with tissues, and potential exposure levels. Indicators of (i) a potential for high exposure, (ii) prospective toxicity or, on the contrary, (iii) the likelihood for loss of nanoproperties are summarized in Table 2. As far as exposure patterns are concerned, it is important to note that with increasing nano-applications to a variety of medicinal and consumer products, NPs in food may not be the only source of oral exposure to ENMs since ingestion of diverse nanosized particles may concurrently result from use of drugs and, accidentally, of sunscreens, lipsticks, skin creams, and toothpastes.

\section{Detection and characterization of nanomaterials}

Besides the size and the chemical composition, the unique properties of nanostructured materials depend on a number of other physicochemical parameters, such as shape, surface properties, crystalline phase, density, porosity, solubility or (photo)catalytic activity (if any). Adequate characterization of an ENM is essential for relating its behavior and functional properties to an unequivocally established identity and help designing new materials with definite features for specific purposes. At the same time, a comprehensive characterization is essential to understand the biological properties of ENMs and assess their safety. In the latter case, it is important that at least the most important physicochemical parameters are determined not only for the ENM per se, but also in the product (e.g., the food matrix) and under testing conditions. The information is needed to assess whether the material tested is representative and relevant for the exposure from the intended use, for comparing materials tested in different products and between different manufacturers.

In comparing the properties of a pristine ENM with those of the same material in food products, an issue that has to be considered is the lifetime of the ENM, from 


\begin{tabular}{|c|c|c|c|c|}
\hline Particle (primary size) & Duration & Dose (species) ${ }^{\mathrm{a}}$ & Results & Reference \\
\hline $\mathrm{Ag}(60 \mathrm{~nm})$ & 28 days & $\begin{array}{l}30,300 \\
1000 \mathrm{mg} / \mathrm{kg} \text { bw/day (r) }\end{array}$ & $\begin{array}{l}\text { Changes in ALP and } \\
\text { cholesterol indicating mild } \\
\text { liver damage }\end{array}$ & Kim et al., 2008 \\
\hline $\mathrm{Ag}(56 \mathrm{~nm})$ & 90 days & $\begin{array}{l}30,125 \\
500 \mathrm{mg} / \mathrm{kg} \text { bw/day }(\mathrm{r})\end{array}$ & $\begin{array}{l}\text { Changes in ALP and } \\
\text { cholesterol indicating mild } \\
\text { liver damage, bile-duct } \\
\text { hyperplasia }\end{array}$ & Kim et al., 2010 \\
\hline Ag $(22-42-71-323 \mathrm{~nm})$ & $\begin{array}{l}14 \text { days } \\
\text { ( } 28 \text { days for } 42 \mathrm{~nm}-\mathrm{NPs} \text { ) }\end{array}$ & $1 \mathrm{mg} / \mathrm{kg}$ bw/day $(\mathrm{m})$ & $\begin{array}{l}\text { Inflammatory responses, } \\
\text { liver and kidney toxicity }\end{array}$ & Park et al., 2010 \\
\hline $\mathrm{Ag}(14 \mathrm{~nm})$ & 28 days & $9 \mathrm{mg} / \mathrm{kg}$ bw/day $(\mathrm{r})$ & $\begin{array}{l}\text { Similar organ distribution of } \\
\text { ionic Ag and Ag NPs. } \\
\text { Besides the intestinal } \\
\text { system, largest } \\
\text { concentrations in liver and } \\
\text { kidneys. Ag also found in } \\
\text { lungs and brain }\end{array}$ & Loeschner et al., 2011 \\
\hline $\mathrm{Ag}(14 \mathrm{~nm})$ & 28 days & $2.25,4.5,9 \mathrm{mg} / \mathrm{kg}$ bw/day $(\mathrm{r})$ & $\begin{array}{l}\text { Toxicity of ionic Ag but not } \\
\text { of an equimolar Ag-NP dose }\end{array}$ & Hadrup et al., 2012 \\
\hline $\begin{array}{l}\mathrm{Ag}(<20 \mathrm{~nm},<15 \mathrm{~nm} \\
\text { PVP-coated) }\end{array}$ & 28 days & $9 \mathrm{mg} / \mathrm{kg}$ bw/day (r) & $\begin{array}{l}\text { In vivo formation of } \mathrm{Ag} \text { NPs } \\
\text { also for treatment with ionic } \\
\mathrm{Ag} \text {, long retention of } \mathrm{Ag} \text { in } \\
\text { brain and testis }\end{array}$ & van der Zande et al., 2012 \\
\hline $\mathrm{SiO}_{2}(7,15-20 \mathrm{~nm})$ & $\begin{array}{l}28 \text { days } \\
\text { (84 days highest dose) }\end{array}$ & $\begin{array}{l}100,500,1000 \\
2500 \mathrm{mg} / \mathrm{kg} \mathrm{bw} / \text { day }(\mathrm{r})\end{array}$ & $\begin{array}{l}\text { Liver fibrosis, differences } \\
\text { between the two pyrogenic } \\
\text { SAS types studied }\end{array}$ & van der Zande et al., 2014 \\
\hline $\mathrm{SiO}_{2}(\sim 20 \mathrm{~nm})$ & 5 days & $20 \mathrm{mg} / \mathrm{kg}$ bw/day $(\mathrm{r})$ & $\begin{array}{l}\text { Distribution in liver and } \\
\text { spleen, differences between } \\
\text { the precipitated and } \\
\text { pyrogenic SAS studied }\end{array}$ & $\begin{array}{l}\text { Cubadda et al., } \\
\text { in preparation }\end{array}$ \\
\hline $\mathrm{TiO}_{2}(5-6 \mathrm{~nm})$ & 90 days & $2,5,10 \mathrm{mg} / \mathrm{kg}$ bw/day $(\mathrm{m})$ & $\begin{array}{l}\text { Chronic spleen injury and } \\
\text { reduction of immune } \\
\text { capacity }\end{array}$ & Sang et al., 2012 \\
\hline $\mathrm{TiO}_{2}(5-6 \mathrm{~nm})$ & 90 days & 10 mg/kg bw/day $(\mathrm{m})$ & $\begin{array}{l}\text { Ovarian damage, } \\
\text { imbalance of mineral } \\
\text { elements and sex } \\
\text { hormones, decreased } \\
\text { fertility/pregnancy rate and } \\
\text { oxidative stress }\end{array}$ & Gao et al., 2012 \\
\hline $\mathrm{TiO}_{2}(5-6 \mathrm{~nm})$ & 90 days & $2,5,10 \mathrm{mg} / \mathrm{kg}$ bw/day $(\mathrm{m})$ & $\begin{array}{l}\text { Testicular lesions, } \\
\text { spermatogenesis } \\
\text { suppression, sperm } \\
\text { malformations, and } \\
\text { alterations in serum sex } \\
\text { hormone levels }\end{array}$ & Gao et al., 2013 \\
\hline $\mathrm{TiO}_{2}(5-6 \mathrm{~nm})$ & 90 days & $2,5,10 \mathrm{mg} / \mathrm{kg}$ bw/day $(\mathrm{m})$ & $\begin{array}{l}\text { Deposition in ovary, fertility } \\
\text { reduction and ovary injury } \\
\text { associated with alteration of } \\
\text { inflammation-related or } \\
\text { follicular atresia-related } \\
\text { cytokines }\end{array}$ & Zhao et al., 2013 \\
\hline $\mathrm{TiO}_{2}(<25 \mathrm{~nm})$ & 5 days & $1,2 \mathrm{mg} / \mathrm{kg}$ bw/day $(\mathrm{r})$ & $\begin{array}{l}\text { Sex-related effects in } \\
\text { endocrine-active tissues, } \\
\text { particle deposition in spleen }\end{array}$ & Tassinari et al., 2014 \\
\hline
\end{tabular}




\begin{tabular}{|c|c|}
\hline $\begin{array}{l}\text { Indicators of a potential for } \\
\text { high exposure }\end{array}$ & $\begin{array}{l}\text { High production volume for the field of application } \\
\text { High mobility of the nanoform in organisms (probability of internal exposure) (e.g., transport via } \\
\text { macrophages; transport through cell membranes, blood-brain barrier and/or placenta; drug delivery } \\
\text { systems) and mobilization potential (e.g., infiltration, sorption, complex formation) } \\
\text { Targeted or controlled release } \\
\text { Persistence/stability (e.g., in water, fat, and body fluids, lack of solubility/degradation) } \\
\text { Bioaccumulation }\end{array}$ \\
\hline $\begin{array}{l}\text { Indicators of potential } \\
\text { toxicity }\end{array}$ & $\begin{array}{l}\text { High level of reactivity (e.g., catalytic, chemical, biological) } \\
\text { Complex morphology (e.g., rigid, long tubes or fibres, high aspect ratio nanomaterials, fullerenes, crystal } \\
\text { structure, porosity). ENM with cores and shells of different biopersistence (e.g., multifunctional ENM) } \\
\text { Interactions with biomolecules such as enzymes, DNA, receptors, 'Trojan horse' effect } \\
\text { Complex transformations (e.g., aging, changes of surface properties, porosity) or metabolites (e.g., changes } \\
\text { to or loss of coating, 'dynamic corona') } \\
\text { ENM intended to be used as antimicrobials (e.g., unintended consequences on the gut flora) }\end{array}$ \\
\hline $\begin{array}{l}\text { Indicators of reduced } \\
\text { likelihood of adverse } \\
\text { effects and/or loss of nano- } \\
\text { properties }\end{array}$ & $\begin{array}{l}\text { Increased rate of dissolution (e.g., in water, food/feed matrix or body fluids) } \\
\text { Increased rate of degradability (e.g., biological or photocatalytic) to non-nanoform degradation products } \\
\text { Presence of strongly bound aggregates (e.g., determined by conditions of production), fixed, permanent } \\
\text { bonding in matrices (e.g. stability of matrix, type of bond, end-of-life behavior) }\end{array}$ \\
\hline
\end{tabular}

manufacturing to addition into the food to subsequent processing and storage. When the ENM is incorporated into the food matrix, changes in $\mathrm{pH}$, ionic strength, ionic composition, processing (e.g., cooling, heating, mechanical stress) can lead to a substantial alteration of the properties of the ENM. Food constituents interacting with the particles present also play a role in this respect.

The specifications of an ENM are important as they may critically influence the outcome of toxicity tests and overall risk assessment (e.g., different sizes and shapes of ENMs with the same chemical composition may lead to different effects) and are needed to interpret the outcome of toxicological studies carried out by different laboratories. Moreover, such information contributes to the knowledge base which in the future can be used for extrapolation or read-across procedures (EFSA, 2011). Important parameters for the characterization of ENMs and related analytical techniques are summarized in Table 3. Besides those listed, other parameters may be relevant for specific ENMs and applications. An ENM introduced into a liquid medium forms a dispersion, where the liquid and the ENM coexist (the ENM is suspended in the medium). Not all the ENMs, however, are totally insoluble and for particles that slowly dissolve (e.g., Ag) determining the solubility and dissolution rate constants is key. Other parameters that may be important are viscosity, dustiness, porosity, chemical reactivity, catalytic and photocatalytic activity. Overall, the selection of physicochemical parameters will depend on the nature, functionalities, and intended uses of the ENM. For example, if a particular shape of an ENM is technologically important or raises a toxicological concern (e.g., a rigid needle shape), then the determination of shape will become a mandatory parameter for measurement.

The selection of the optimal method for measurement of a property will be dependent on the type of ENM (the chemical characterization of an inorganic ENM will need a different analytical technique compared to an organic one) as well as the measurement environment (e.g., raw material, in a liquid, in solid food, in food packaging). Thus the choice of parameters and analytical methods will need to be made on a case-by-case basis.

The techniques listed in Table 3 have advantages and limitations. EM methods (SEM, TEM) are useful in visualizing NPs as well as determining their size, aggregation state, structure and shape. Indeed, microscopy analysis is an indispensable tool for the characterization of nanoscale objects and plays a major role in a variety of nanoscience- and nanotechnology-related disciplines, from materials science, to biology and food technology. TEM requires very thin specimens for the electrons to pass through. TEM also requires vacuum conditions and, therefore, can not handle liquid samples. To overcome this, cryo-TEM has been used that can handle frozen samples. The use of Wet-SEM has also been reported (Tiede et al., 2008), which can handle liquid samples in a specially designed capsule that allows characterization of NPs in liquid samples. SPM tools, such as AFM, can also be used to examine liquid samples. The availability of a variety of different microscopies offers many possibilities for the identification and characterization of specific ENMs in different sample types. However, high throughput use of SPM tools and EM methods is currently limited due to the length of time required for sample processing. The use, effectiveness and reliability of SPM based techniques are discussed in greater detail in the following section.

Moreover, light scattering methods are commonly used to measure size and size distribution of particles as well as agglomerates and aggregates in suspensions. However, accuracy of light scattering measurements is dependent on factors such as sample preparation and monodispersity and these techniques are applied to raw materials rather than ENMs in final products. 


\begin{tabular}{|c|c|c|c|}
\hline Parameter & Requirements & Description & Analytical techniques \\
\hline Chemical composition & Essential & $\begin{array}{l}\text { Information on chemical composition of } \\
\text { the ENM. } \\
\text { This may include purity, nature of } \\
\text { impurities, coatings or surface moieties, } \\
\text { encapsulating materials, processing } \\
\text { chemicals, dispersing agents and/or other } \\
\text { formulants, e.g., stabilizers. }\end{array}$ & $\begin{array}{l}\text { Elemental analysis: ICP-MS, AES, AAS, } \\
\text { XPS, EDX, NMR } \\
\text { Molecular composition: MS (ToF, QqQ) } \\
\text { with suited ionization techniques (e.g., } \\
\text { MALDI, ESI), coupled with separation } \\
\text { techniques (e.g., HPLC, GC, CE), NMR, } \\
\text { FT-IR. } \\
\text { Shell/core composition (e.g., } \\
\text { encapsulates, micelles): a suitable } \\
\text { technique above, after disintegration of } \\
\text { the particles and separation of the } \\
\text { components by, e.g., HPLC, SEC, CE, } \\
\text { HDC. }\end{array}$ \\
\hline $\begin{array}{l}\text { Particle size } \\
\text { (primary/secondary) }\end{array}$ & Essential & $\begin{array}{l}\text { Information on primary particle size, size } \\
\text { of agglomerates/aggregates, size range } \\
\text { and number size distribution }\end{array}$ & $\begin{array}{l}\text { Electron Microscopy (TEM, SEM, STEM) } \\
\text { and Diffraction (ED) with related } \\
\text { techniques } \\
\text { Scanning Probe Microscopies (AFM and } \\
\text { STM based techniques) } \\
\text { X-ray Diffraction (XRD) } \\
\text { Separation techniques (e.g. FFF, HDC, } \\
\text { SEC, HPLC) with suitable detectors, DMA- } \\
\text { IMS } \\
\text { Centrifugation tecniques (e.g. ANUC) } \\
\text { Spectroscopy - e.g. XRD, SAXS (for crystal } \\
\text { size, crystallite size) } \\
\text { Light (laser) scattering- e.g., DLS, MALS, } \\
\text { SLS; PCS, NTA }\end{array}$ \\
\hline Particle concentration & Essential & $\begin{array}{l}\text { Information on concentration in terms of } \\
\text { particle number }\end{array}$ & $\begin{array}{l}\text { Light scattering methods (for dispersions) } \\
\text { sp-ICP-MS (inorganic ENMs) } \\
\text { Particle concentration in pure dry powders } \\
\text { may be calculated from particle size, mass } \\
\text { concentration and density of the material }\end{array}$ \\
\hline Mass concentration & Essential & $\begin{array}{l}\text { Information on concentration in terms } \\
\text { particle mass per volume when in } \\
\text { dispersion and per mass when as dry } \\
\text { powder }\end{array}$ & $\begin{array}{l}\text { Suited techniques from those listed under } \\
\text { chemical composition, e.g., MS (ICP-MS) }\end{array}$ \\
\hline Density & $\begin{array}{l}\text { Essential for } \\
\text { granular materials }\end{array}$ & $\begin{array}{l}\text { Information on density/porosity of } \\
\text { unformulated ENMs }\end{array}$ & $\begin{array}{l}\text { AEM, CFM, gravimetry, centrifugal } \\
\text { sedimentation (for suspensions) }\end{array}$ \\
\hline Specific surface area & $\begin{array}{l}\text { Essential for } \\
\text { dry powders }\end{array}$ & $\begin{array}{l}\text { Information on specific surface area of the } \\
\text { ENM }\end{array}$ & BET, SAXS \\
\hline Surface chemistry & $\begin{array}{l}\text { Essential } \\
\text { (for ENM with surface } \\
\text { modifications) }\end{array}$ & $\begin{array}{l}\text { Information on ENM surface - including } \\
\text { any chemical/biochemical modifications } \\
\text { that could modify the surface reactivity, or } \\
\text { add a new functionality }\end{array}$ & $\begin{array}{l}\text { Any of the suitable chemical } \\
\text { characterization techniques listed above }\end{array}$ \\
\hline Surface charge & Essential & Information on zeta potential of the ENM. & $\begin{array}{l}\text { Electrophoresis, e.g., CE, LDE (zeta } \\
\text { potential) }\end{array}$ \\
\hline Redox potential & $\begin{array}{l}\text { Essential for } \\
\text { inorganic ENMs }\end{array}$ & $\begin{array}{l}\text { Information on redox potential. } \\
\text { Conditions under which redox potential is } \\
\text { measured need to be documented }\end{array}$ & Potentiometry \\
\hline
\end{tabular}




\begin{tabular}{|llll|}
\hline Table 3 (continued) & & \\
\hline Parameter & Requirements & Description & Analytical techniques \\
\hline Solubility & Essential & Information on dissolution of the ENM in & sp-ICP-MS (inorganic ENMs) \\
& & relevant solvents and partitioning between & $\begin{array}{l}\text { Centrifugation and filtration techniques } \\
\text { (dialysis, CFUF) }\end{array}$ \\
& aqueous and organic phase & Other techniques (voltammetry, diffusive \\
& & gradients in thin films) \\
\hline
\end{tabular}

Overall, despite the availability of an impressive number of microscopies and related techniques, there are many metrological issues that have to be yet better defined at the nanoscale. Nanometrology is a key enabling technology for quality control at the nanoscale and, in the last years, many governments worldwide have promoted nanotechnology policies and have taken the preliminary steps towards nanometrology strategies, for example in support of pre-normative $\mathrm{R} \& \mathrm{D}$ and standardization work (Leach et al., 2011).

In such a context, the measurement of size at the nanoscale is only a facet of the problem, and, probably, not the most complex. Besides shape and particle size, the functional properties of ENMs (and most likely, also biological ones) also depend on the crystal structure. Therefore, phase identification and unit cell determination are important in the characterization and quality control of ENMs. For this purpose, diffraction techniques operating in the reciprocal space are used. Diffraction analyses may be carried out using either light of very short wavelength, such as X-rays, or matter waves like electrons (and neutrons) with wavelengths in the order of the atomic spacing or much smaller (Cowley, 1975). X-ray powder diffraction is the most used technique in crystal structure analysis for bulk materials, but is less used in the characterization of ENMs for intrinsic limits, as X-rays are only scattered by the electrons of scattering atoms meaning that relatively large volume of material and long data acquisition times are required, resulting in the incapability to perform structural analyses at the nanoscale. These limits are not present in the case of electron diffraction, being electron cross sections $10^{4}-10^{5}$ times larger than that of X-ray due to the strong interactions between electrons and nuclei of the scattering centers. As a result, it is possible to obtain electron diffraction patterns from very tiny diffracted volume even with short exposure times (e.g., a few seconds) and it is possible to perform sophisticated and reliable structural analysis at the nanoscale (Terranova et al., 2009), making also possible the characterization of single crystallites (Honglong, Guling, Bin, Minting, \& Wenzhong, 2013). The capabilities and performances of the large variety of ED techniques today available (Rossi, Manno, Orlanducci, Serra, \& Terranova, 2011) represent a powerful, and sometimes unique, tool for the structural analysis and complete identification of ENMs.

The analytical determination of ENMs in complex matrices such as food presents several metrological and conceptual challenges (Linsinger et al., 2013). Size information is of course the most critical, since it is size that makes a particle an NP. It is often advised that the size parameter is measured by at least two independent techniques, one being electron microscopy. However, it should be kept in mind that (i) non-spherical particle are characterized by multiple 'sizes', (ii) these sizes may differ between the dried or dispersed state of a particle, and (iii) different particle size analysis methods measure fundamentally different parameters, which are nevertheless all called 'size'. For instance classical TEM typically measures the lateral dimensions of a $2 \mathrm{D}$ projection of the particle whereas DLS measures the hydrodynamic diameter of particles and expresses it as the diameter of a spherical particle that has the same Brownian motion behavior in suspension. Since measured sizes are method-defined, the term 'size' of a particle is meaningless without specification of the type of size (e.g., hydrodynamic diameter) and the method used to obtain this information, and unless particles are perfect spheres (which rarely is the case) measurements from different methods are by definition not comparable. Another challenge associated with the determination of the size of a particle is the fact that the sizes of ENMs in complex matrices often follow rather broad distributions and there are currently no reliable methods available for the determination of accurate number-based size distributions in the size range $1-100 \mathrm{~nm}$. This is a critical point especially when it comes to the nano-definitions proposed for regulatory purposes. In 2011, the European Commission made a recommendation for an overarching definition of nanomaterial (Commission Recommendation 2011/696/ EU), which should be used in EU legislation and adapted to the different regulatory areas, including food and FCMs, to derive sector specific definitions. The key concept in this definition is actually the percent threshold of particles in the number size distribution with one or more external dimensions in the size range $1-100 \mathrm{~nm}$. If $\geq 50 \%$ of particles are in such size range the material is a nanomaterial. The number size distribution threshold of $50 \%$ may be replaced by one between 1 and $50 \%$ in specific cases, where warranted by concerns for the environment, health, safety or competitiveness.

Also the metrological definition of the 'quantity' of an ENMs is not obvious. Unless the particles are nearspherical and of uniform and known density, directly converting quantities based on mass (mass fractions) to numbers (number concentrations) is unlikely to produce 
accurate results and thus mass based, number based, and intensity based results, which are by definition not comparable, may also be virtually non-convertible.

Notwithstanding these difficulties, a generic approach for the validation of methods for detection and quantification of NPs in food samples has been put forward (Linsinger et al., 2013) and many efforts have been recently made to advance the analytical determination of ENMs either directly added to food or released into food from its packaging. A critical aspect, of course, is sample preparation, which may consist in either extracting the NPs from the embedding matrix (e.g., by enzymatic or chemical methods) or removing, or at least simplifying, the matrix itself. Dilution with water and sonication may be sufficient for liquid food, whereas in some case defatting could be necessary. It is necessary to check that the treatment method does not modify the original particle size distribution and this calls for a carefully executed and documented sample preparation, allowing to track possible artifacts (Calzolai, Gilliland, \& Rossi, 2012). In general, the most critical issues in this area are extraction challenges, the presence of analytical artifacts caused by sample preparation, problems of distinction between natural and engineered NPs and lack of standard and reference materials (Roebben et al., 2013).

As previously discussed, when measuring NPs in complex media it is not only necessary to generate data on average size and mass concentration, since the size distribution and possibly other properties of the particles have to be characterized. No single technique can provide all this information, so a range of analytical techniques is required. As far as size and size distribution is concerned, electron microscopy remains a reference method, with TEM providing accurate measurement of particles down to the low nanorange besides giving morphological information. Electron microscopy-based methods that have been, or have the potential to be, applied to ENM imaging in foodstuffs have been reviewed and an overview of approaches to sample preparation (drying, chemical treatment, fixation, and cryogenic methods) along with a strategy for selecting the most appropriate method for a particular foodstuff have been given (Dudkiewicz et al., 2011).

For inorganic ENMs, ICP-MS-based techniques are attractive being able not only to measure size and size distributions, but to also determine the chemical identity of the particles. Hyphenated ICP-MS-based methods have been increasingly used in this respect, for instance HDC-ICPMS for the determination of SAS (Dekkers et al., 2011) or asymmetric flow FFF-ICP-MS for the determination of nanoclays (Schmidt et al., 2009) or SAS (Heroult, Nischwitz, Bartczak, \& Goenaga-Infante, 2014) in various food matrices. A different approach consists in sp-ICPMS, which has been used either alone (R. J. Peters et al., 2014), or in combination with asymmetric flow FFF (Loeschner et al., 2013), for the determination of silver NPs in chicken meat. Due to the positive features mentioned above, along with speed allowing for a reasonable sample throughput, ICP-MS-based techniques appear as the most promising for the routine determination of inorganic ENMs in food. So far, three interlaboratory studies have been carried out on the determination of Ag particles in food simulants/matrices, two of them by sp-ICP-MS and one by FFF-ICP-MS (Cubadda, Aureli, D'Amato, Raggi, \& Mantovani, 2013; Linsinger, Peters, \& Weigel, 2014). A limitation of ICP-MS-based techniques is represented by the determination on certain oxide ENMs $\left(\mathrm{SiO}_{2}, \mathrm{TiO}_{2}\right)$, mainly due to polyatomic interferences affecting $\mathrm{Si}$ and Ti masses, but solutions to overcome these challenges are foreseen (Aureli et al., 2012; Tassinari et al., 2014).

Organic ENMs suitable for application in food are lipid-, protein- or polysaccharide-based particles. The identification and characterization of organic NPs in food sample preparation may range from very simple to a separation step using chromatography, FFF or ion-mobility separation. Subsequently, PC and especially MS techniques such as MALDI-ToF-MS seem suitable techniques for characterizing a wide variety of organic NPs (R. Peters et al., 2011).

The discrimination between natural/accidental nanomaterials and ENMs with the same chemical composition in food can be important for the selective determination of the latter, e.g., for regulatory purposes. It is anticipated, however, that such an analysis is extremely complex and certainly requires the use of a suite of imaging and analytical techniques.

Overall, the analytical determination of ENMs in food poses a number of technical challenges, especially when real unknown samples - i.e. food products for which no information about the presence of ENMs and their nature is available - are to be analyzed. Despite the fact that labeling of ENMs used as ingredients will become mandatory in the European Union as of December 2014, at present only few methods for the analytical determination of nanomaterials in specific food matrices have been developed and validated.

\section{Scanning probe microscopy based techniques for nanoscale characterization of food}

The well-established tools and techniques for the characterization of materials at the nanoscale, widely applied in nanotechnology, are being increasingly used to study 'natural' food products from microscale to nanoscale. Almost all the available microscopy techniques have been used to study foods and food derived materials at different size scales. Indeed, a more comprehensive understanding of food structures from micro down to nano (i.e., macromolecular) scale has been attained by the complementary use of different types of microscopies. In addition to more conventional ones, i.e., LMs - bright field and polarized LM, fluorescence microscopy, CLSM (Dufour, 2011; El-Bakry \& Sheehan, 2014; Sheen, Bao, \& Cooke, 2008; van de Velde, van Riel, \& Tromp, 2002), EFLM (Peighambardoust, Dadpour, \& Dokouhaki, 2010) - and EMs - SEM and 
TEM (El-Bakry \& Sheehan, 2014), cryo-SEM and cryoTEM, STEM, ESEM and ASEM, EDX spectroscopy and microanalysis (Gatti, Tossini, Gambarelli, Montanari, \& Capitani, 2009; B. James, 2009), also SPM techniques AFM, SNOM, STM (Liu \& Cheng, 2011; H. Yang et al., 2007) - have been put forward and are being increasingly applied for nanocharacterization of food.

SPM techniques have been proposed as tools for visualization of ultrastructures and to characterize physical properties of foods and food-derived samples at the nanoscale. Due to its relatively wide diffusion and straightforward sample preparation, AFM is the most widely used SPM technique in food-related studies (Liu \& Cheng, 2011; H. Yang et al., 2007). In particular, AFM has been used to analyze morphological and structural features of samples, e.g., different polysaccharides (Funami, 2010), starch granules, nanocrystals and molecules (An, Yang, Liu, \& Zhang, 2008; Baker, Miles, \& Helbert, 2001; Neethirajan, Tsukamoto, Kanahara, \& Sugiyama, 2012; Ridout, Gunning, Parker, Wilson, \& Morris, 2002; Ridout, Parker, Hedley, Bogracheva, \& Morris, 2003; Ridout, Parker, Hedley, Bogracheva, \& Morris, 2006), proteins (Fyfe et al., 2011) and food biopolymers. The analysis of AFM images may enable the quantitative evaluation of structural parameters of food derived samples. As an example, backbone and branch lengths of alkali-soluble pectin which has undergone a process of mild acid hydrolysis have been recently deduced from AFM images and correlated to the reduction of predominant sugars (Zhang, Cui, Xiao, \& Wang, 2014). By probing the surface of samples with a nanometrical tip, AFM has been used to probe molecular interactions via force spectroscopy (Morris, Woodward, \& Gunning, 2011). Moreover, AFM has been demonstrated as an ideal platform to develop advanced techniques for nanomechanical characterization of samples (Passeri, Rossi, Tamburri, \& Terranova, 2013), the potential of which for the analysis of Young's modulus, complex elastic modulus, hardness, tip-sample adhesion force has been only marginally explored in food derived samples (Goode, Bowen, Akhtar, Robbins, \& Fryer, 2013; Morton et al., 2003; Scramin et al., 2011; Zdunek \& Kurenda, 2013). As an example, Fig. 6 (Berquand, Gaillard, \& Bouchet, 2009) shows the characterization of an ultrathin section of a resin-embedded wheat aleurone tissue in liquid environment using epifluorescence combined with torsional harmonics AFM (HarmoniX ${ }^{\mathrm{TM}}$, Bruker Inc.), an AFM-

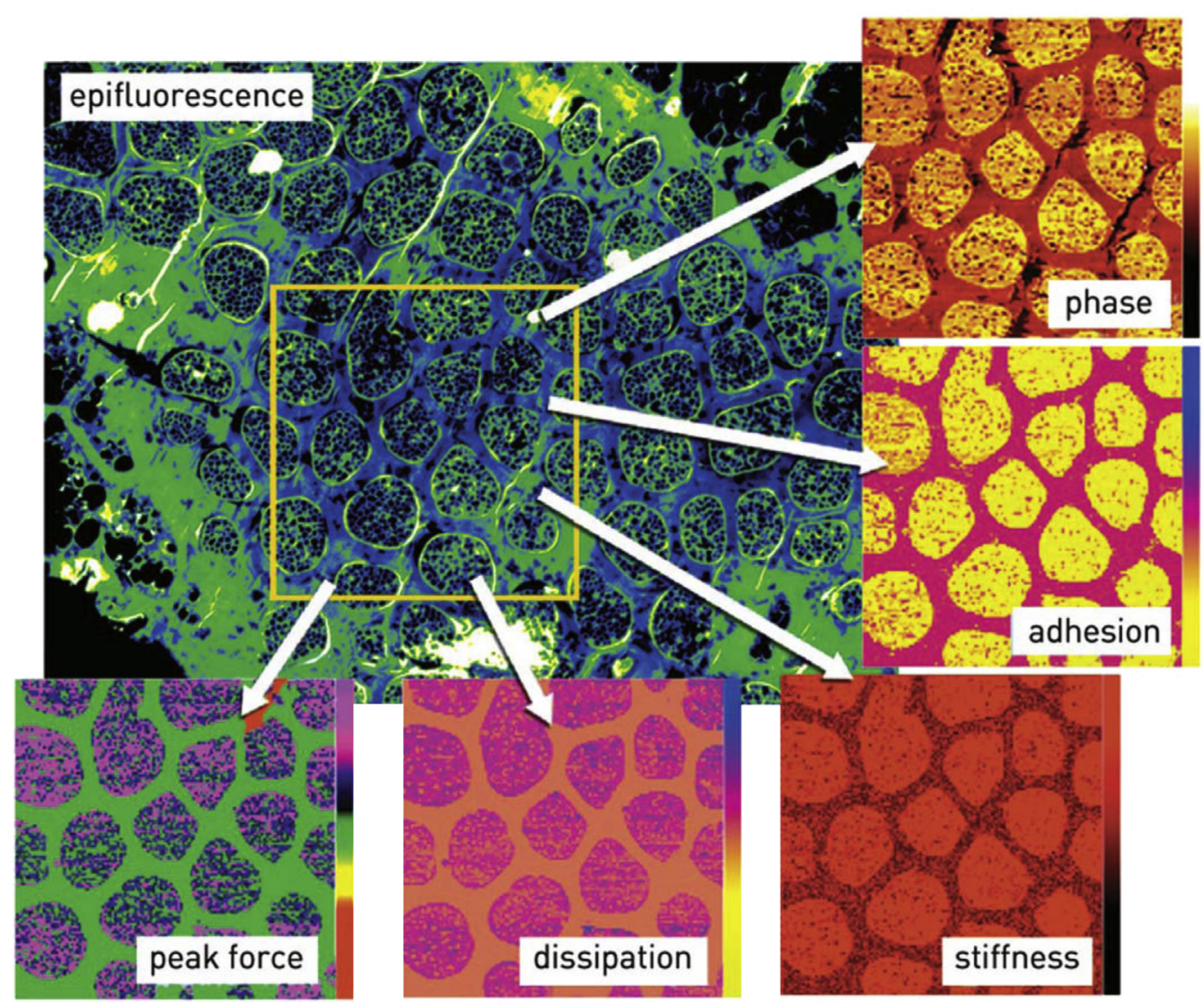

Fig. 6. Nanoscale mechanical characterization of an ultrathin section of a resin-embedded wheat aleurone tissue using epifluorescence combined with torsional harmonics AFM (HarmoniX ${ }^{\mathrm{TM}}$, Bruker Inc.) imaging in liquid environment. The yellow frame represents the AFM scan location where nano-mechanical measurement was performed. Simultaneously to topography, phase (scale $=30$ deg), adhesion, peak force, dissipation, and elastic modulus (scale $=5 \mathrm{GPa}$ ) were recorded (Berquand et al., 2009). Figure courtesy of Bruker Corporation. 
based technique which allows one to perform the quantitative characterization of mechanical parameters of soft samples (mainly, elastic modulus, tip-sample adhesion force and tip-sample dissipation) with nanometrical lateral resolution (Sahin \& Erina, 2008; Sahin, Magonov, Su, Quate, \& Solgaard, 2007). Also, thermal characterization at the nanoscale has been performed on caramel using SThM (Morton et al., 2003). Finally, even if only marginally, other SPM techniques have been used to study food derived samples, i.e., SNOM for the characterization of proteinsurfactant interactions by acquiring fluorescence images at sub-micrometer scale (Morris, 2004) and STM for the investigation of high molecular subunits of wheat glutenin (Tatham et al., 1999).

The use of SPM is admittedly only partially common in food analysis (as a reference, about 700 papers can be found through Web of Science ${ }^{\mathrm{TM}}$ searching AFM and 'food' in the topics). Conversely, a much wider literature exists dealing with the investigation of food samples by EMs (about 11,800 articles can be found through Web of Science $^{\mathrm{TM}}$ by searching for EM and 'food' in the topics). Among these, SEM and AFM have been used complementary to study wheat starch granules (Barrera et al., 2013), buckwheat starch (Neethirajan et al., 2012) and milk protein concentrate (Fyfe et al., 2011). EMs and CLSM have been employed in the analysis of dextran-rice starch mixtures (Achayuthakan, Suphantharika, \& BeMiller, 2012), milk gel and cheese curd (Ong, Dagastine, Kentish, \& Gras, 2011), and cheese samples (El-Bakry \& Sheehan, 2014). LM, EMs and AFM have been applied to the study of structural alterations induced in grape berry fruits by hydrogen peroxide, UVC irradiation and ultrasound treatments (Fava et al., 2011). Other well-established techniques that have been employed in food analysis are Raman spectroscopy (Celedón \& Aguilera, 2002; Herrero, 2008; D. Yang \& Ying, 2011) or XPS, the latter used for instance in combination with cryo-SEM and ESEM on chocolate samples (B.J. James \& Smith, 2009).

\section{Applications of nanotechnologies in the food sector and EU regulatory framework}

Nanotechnologies are enabling technologies that have opened up new avenues of $R \& D$ in a number of fields. In the agri-food sector, they are being used as means to understand how physicochemical characteristics of nano-sized substances can change the structure, texture and quality of foodstuffs or can be employed for obtaining new food packaging materials with improved mechanical, barrier and antimicrobial properties (Chaudhry et al., 2008). Convergence of nanotechnology with other technologies is also leading to further innovations that are predicted to have a major impact on food production, processing, storage, transportation, traceability and safety. For example, integration of biotechnology, nanotechnology and IT has opened up new opportunities for the development of nano-biosensors for the detection of pathogens and contaminants in food.

Even if the applications of nanotechnology in the agrifood sector are only new emergent, they are predicted to grow rapidly in the coming years and many of the world's largest food companies are reported to have been actively exploring the potential of nanotechnology for use in food production or food packaging. Three main categories of products/applications can be identified (Table 4). The first is represented by the applications for agricultural production, which include nano formulated agrochemicals (e.g., fertilizers, pesticides, biocides, veterinary medicines) for improved efficacy, durability, controlled delivery, and reduction in the amounts of active ingredients that need to be used, animal feeds (e.g., fortified with nanosupplements, antimicrobial additives, detoxifying materials e.g. mycotoxin-binding ENMs), and nano-biosensors for animal disease diagnostics. The second consists in the applications for food processing and involves manufacture of ENMs intended for direct consumption, such as nanosized ingredients, additives, nutritional supplements, and functional foods. The third category are the ENMs that are incorporated into products which come into contact with food (e.g., packaging materials).

During primary production nano-formulated agro-chemicals are employed primarily to increase the efficacy of the agro-chemicals compared to conventional formulations. For instance, in the last two years, research into nanopesticide development has considerably increased and a number of formulation types have been proposed including nanoemulsions, nanocapsules (e.g., polymer-based formulations), and products containing pristine engineered NPs, such as metals, metal oxides, and nanoclays (Kah \& Hofmann, 2014; Kookana et al., 2014).

A major focus of current nanotechnology applications in food is the development of nanostructured (or nanotextured) food ingredients and delivery systems for nutrients and supplements. A variety of processes are being utilized for these purposes, including nano-emulsions, surfactant micelles, emulsion bilayers and reverse micelles (Morris, 2011). For instance nano-micelle based carriers for nutraceuticals and nutritional supplements are currently available. Another major area of current nanotechnology applications is nanoencapsulation of food ingredients and additives to provide protective barriers, flavor and taste masking, controlled release, and better dispersability for water-insoluble food ingredients and additives (Cushen et al., 2012). A number of nutraceuticals and nutritional supplements containing nano-ingredients and additives (e.g., vitamins, antimicrobials, antioxidants) are currently available. These products typically claim enhanced absorption and bioavailability of nano-sized ingredients in the body.

Nanotechnology derived food packaging materials are the largest category of current nanotechnology applications for the food sector (Bradley, Castle, \& Chaudhry, 2011). Relatively low levels of NPs are sufficient to change the 


\begin{tabular}{|c|c|c|}
\hline Nanotechnology & Application & Function \\
\hline \multicolumn{3}{|l|}{ Agricultural production } \\
\hline Nanosensors & $\begin{array}{l}\text { Nanosprays } \\
\text { Hand-held devices }\end{array}$ & $\begin{array}{l}\text { Binding and coloring micro-organisms; } \\
\text { Detection of contaminants, mycotoxins and } \\
\text { microorganism }\end{array}$ \\
\hline Nanopesticides & $\begin{array}{l}\text { Nano-emulsions, encapsulates } \\
\text { Triggered release nano-encapsulates }\end{array}$ & $\begin{array}{l}\text { Increased efficacy and water solubility } \\
\text { Triggered (local) release }\end{array}$ \\
\hline Other nanosized agrochemicals & Nano-sized fertilisers, biocides, veterinary medicines & $\begin{array}{l}\text { Improved delivery of agrochemicals in the field, } \\
\text { better efficacy, better control of application/dose, } \\
\text { less use of solvents in agricultural spraying. }\end{array}$ \\
\hline \multicolumn{3}{|l|}{ Food processing } \\
\hline $\begin{array}{l}\text { Processed nano-structured or } \\
\text { nano-textured food products }\end{array}$ & Nanoemulsions, micelles & $\begin{array}{l}\text { Use of less fat and emulsifiers, stable emulsions, } \\
\text { better tasting food products }\end{array}$ \\
\hline Nano-sized additives & $\begin{array}{l}\text { Organic or inorganic nano-sized additives for food } \\
\text { and health-food applications }\end{array}$ & $\begin{array}{l}\text { Various, but lesser amounts would be needed for a } \\
\text { function or a taste attribute, better dispersability may } \\
\text { also occur }\end{array}$ \\
\hline Nanoencapsulates & $\begin{array}{l}\text { Nano-carrier systems in the form of liposomes or } \\
\text { biopolymer-based nano-encapsulated substances }\end{array}$ & $\begin{array}{l}\text { Providing protective barriers, flavor and taste } \\
\text { masking, controlled release, and better dispersability } \\
\text { for water-insoluble food ingredients and additives }\end{array}$ \\
\hline \multirow[t]{2}{*}{$\begin{array}{l}\text { Nutritional supplements and } \\
\text { nutraceuticals }\end{array}$} & Nano-ingredients and additives & $\begin{array}{l}\text { Enhanced absorption and bioavailability of nano- } \\
\text { sized ingredients in the body }\end{array}$ \\
\hline & Nano-carrier systems for delivery of nutrients & \\
\hline Nanofilters & $\begin{array}{l}\text { Nanofiltration (e.g., porous silica, regenerated } \\
\text { cellulose membranes) }\end{array}$ & $\begin{array}{l}\text { Filtration of water and removal of some undesired } \\
\text { components in food, such as bitter taste in some } \\
\text { plant extracts }\end{array}$ \\
\hline Nanocomposites & $\begin{array}{l}\text { Incorporating nanoparticles into a polymer to form a } \\
\text { composite }\end{array}$ & $\begin{array}{l}\text { Improving strength of materials, durability, barrier } \\
\text { properties, biodegradation }\end{array}$ \\
\hline Nano-coatings & $\begin{array}{l}\text { Incorporating nanomaterials onto the packaging } \\
\text { surface }\end{array}$ & Improving barrier properties \\
\hline 'Active' FCMs & $\begin{array}{l}\text { Incorporating active nanoparticles with intentional } \\
\text { release into- and consequent effect on the packaged } \\
\text { food }\end{array}$ & $\begin{array}{l}\text { Oxygen scavenging, prevention of growth of } \\
\text { pathogens }\end{array}$ \\
\hline 'Intelligent' packaging materials & Incorporating nanosensors for food labelling & $\begin{array}{l}\text { Detection of food deterioration, monitoring storage } \\
\text { conditions }\end{array}$ \\
\hline Surface biocides & $\begin{array}{l}\text { Incorporating nanoparticles }(\mathrm{Ag}, \mathrm{ZnO}, \mathrm{MgO}) \text { on } \\
\text { surfaces }\end{array}$ & $\begin{array}{l}\text { Antimicrobial coating for refrigerators, storage } \\
\text { containers, equipment for food processing, handling } \\
\text { and preparation }\end{array}$ \\
\hline
\end{tabular}

properties of packaging materials without significant changes in density, transparency and processing characteristics. The addition of certain NPs into shaped objects and films has been shown to render them light, fire-resistant and stronger in terms of mechanical and thermal performance, as well as make them less permeable to gases. This has led to the development of a variety of NP reinforced polymers, also termed as 'nanocomposites', which typically contain up to $5 \% \mathrm{w} / \mathrm{w}$ NPs (Llorens, Lloret, Picouet, Trbojevich, \& Fernandez, 2012). The polymer composites incorporating clay NPs were among the first nanocomposites to emerge on the market as improved materials for food packaging. The nanoclay mineral used in these nanocomposites is montmorillonite (also known as bentonite), which is a relatively cheap and widely available natural clay with a natural nano-layer structure that limits the permeation of gases, and provides substantial improvements in gas barrier properties of nanocomposites. The polymers used for clay-polymer nanocomposites are polyamides (PA), nylons, polyolefins, polystyrene (PS), ethylenevinylacetate (EVA) copolymer, epoxy resins, polyurethane, polyimides and polyethylene terephthalate (PET). Polymer nanocomposites incorporating metal or oxide NPs have been developed for antimicrobial 'active' packaging, 
increased strength or UV absorption (an UV absorber such as $\mathrm{TiO}_{2}$ is used to prevent UV-degradation of certain plastics). The metal and oxide ENMs used include silver (Ag), gold $(\mathrm{Au})$, zinc oxide $(\mathrm{ZnO})$, silica $\left(\mathrm{SiO}_{2}\right)$, titanium dioxide $\left(\mathrm{TiO}_{2}\right)$, alumina $\left(\mathrm{Al}_{2} \mathrm{O}_{3}\right)$ and iron oxides $\left(\mathrm{Fe}_{3} \mathrm{O}_{4}, \mathrm{Fe}_{2} \mathrm{O}_{3}\right)$. Based on the antimicrobial action of nanosilver, a number of FCMs have been developed that are claimed to preserve the food materials within longer by inhibiting the growth of microorganisms. The same principle is used to develop refrigerators and food preparation equipment (e.g., cutting boards) with antimicrobial coatings. Other applications in the FCM area exists or are expected especially regarding food production machinery.

The various applications discussed above present different safety issues for consumers, workers and the environment. ENMs that are designed to be deliberately introduced into the food and feed chain and have the potential to be ingested with food ranging from ingredients and additives, to nano-sized components employed in FCMs (if migration into food occurs), to agrochemicals such us nanopesticides (if residues are found in the food as consumed). In the case of FCMs it is essential to assess if the ENMs are released in the food matrix and if this is the case, e.g., for nanosilver, assess if the particles or the ionic form is present using suitable analytical techniques (Echegoyen \& Nerín, 2013; von Goetz et al., 2013). It is inevitable that ENMs with a potential for consumer exposure will have to be assessed for their safety and require separate approval for use in food. A particular case is represented by some additives that have been on the market for a long period of time, with authorizations based on dossiers not (fully) suitable to assess nano-related risks. This is for example the case of E551 $\left(\mathrm{SiO}_{2}\right.$ or SAS) or E171 $\left(\mathrm{TiO}_{2}\right)$, ENMs with a history-of-use that will have to be re-evaluated addressing the presence of a nanoform fraction on the basis of up-todate information.

The assessment of potential risks to human health comprises also occupational exposure. Workers engaged in manufacture, packaging, transport, use and elimination of NM and nanotechnology products may be significantly exposed to ENMs. In workplace exposure, the inhalation route is of major importance in addition to (inadvertent) ingestion and will be the basis for risk assessment. Finally the use of nano-agrochemicals raises a number of issues regarding animal and plant health, and the environment, even though all ENMs included in food and consumer products have to be evaluated for their potential environmental impact as a part of their life cycle assessment. Apart from effects on the environment itself, the potential for reintroduction of ENMs into the food chain has to be assessed.

Currently, there is neither an international regulatory framework for nanotechnologies nor a harmonized or at least uniform approach in national legislations. In most cases, the regulation of nanotechnologies falls within the scope of the so-called horizontal legislation, which is broad and happens to encompass attributes of nanotechnologies even though it does not specifically aim to do so (Cushen et al., 2012). Generally a clear definition to discriminate nanomaterials from other materials is not included in existing horizontal legislation and such a definition is prerequisite to include provisions for nanomaterials in legislation. In a few cases, vertical legislation specifically aimed at regulating nanotechnologies and areas of industries likely to utilize nanotechnologies has been issued, mostly in recent years. In these cases, the vocabulary used makes the legislation more applicable to issues faced by users of nanotechnologies and makes it possible to address the need for safety assessment of ENMs. Globally, it can be said that current differences in world legislation on nanotechnologies regarding safety tests to which products are subjected mean that not all products qualify to the same safety standard. Some nanotechnology-related products may be available on the global market and accessed through the internet and have not had their safety tested before they are marketed.

In the EU, specific regulations establish that if a food ingredient or an FCM results from the application of nanotechnologies it has to undergo a safety assessment before being authorized for use (Cubadda et al., 2013). New nano-food or food ingredients are covered by the Novel Food regulation - implicitly in the current Regulation (EC) $258 / 97$, explicitly in the upcoming regulation that is presently under discussion - whereas additives are dealt with in their respective regulations. For instance Regulation (EC) $1333 / 2008$ states that a new risk assessment by the EFSA is needed for already approved additives when there is a change in particles size due to a new production processes. Furthermore, food additives authorized before 2009 are subject to a re-evaluation programme by the EFSA that includes items containing a nanosized fraction such as E171 (scheduled to be evaluated by 2015) and E551 (scheduled to be evaluated by 2016) (Commission Regulation (EU) No 257/2010). As far as food packaging is concerned, at present there are three authorized nanostructured materials for use in plastic FCMs (Regulation (EU) No 10/2011). Titanium nitride NPs (primary size of approximately $20 \mathrm{~nm}$ ) can be used in polyethylene terephthalate (PET) up to $20 \mathrm{mg} / \mathrm{kg}$ under the condition of absence of migration. Carbon black, composed of primary particles of 10-300 $\mathrm{nm}$ forming agglomerates and aggregates, and SAS, which is composed of primary particles of $1-100 \mathrm{~nm}$ that also tend to agglomerate and aggregate, are the other authorized materials. Regulation (EC) No 450/ 2009 also sets forth that NMs used in active and intelligent FCMs need to be explicitly authorized. In addition, if an $\mathrm{NM}$ is released into food, it needs to be authorized as food additive under Regulation (EC) No 1333/2008.

The only piece of EU food legislation that includes a specific definition of the term 'engineered nanomaterial' is Regulation (EU) No 1169/2011 on the provision of food information to consumers (or 'labeling regulation'), which establishes that as of December 2014 all ingredients 
present in the form of engineered NMs have to be indicated in food labels. The definition as it appears in the regulation itself is not consistent with the overarching definition of NM set forth in the Commission Recommendation 2011/ 696/EU and thus an adaptation is underway. A first proposal for this adaptation has been criticized, inter alia for including an exemption for nanostructured food additives that are already on the market, and has been dismissed so that a new one is currently in preparation.

\section{Conclusions}

The use of nanotechnologies is not limited to the structuring of food constituents at the nanoscale. Nanotechnology applications are expected to bring a range of benefits to the whole food chain, from development of new tastes and textures to reduced use of fats, enhanced absorption of nutrients, innovative and more efficient packaging. Nanotechnology-derived food products are set to grow worldwide and a variety of food ingredients, additives, carriers for nutrients/supplements and FCMs is already available in some countries. Moreover, nanotechnologies are offering potential benefits in fabricating food quality detection tools and several other types of measurement and analytical systems for the traceability of food products.

Although the exciting possibilities offered by the nanotechnologies in the food sector have been in principle demonstrated, the acceptance by consumers remains rather low. This reaction is based on the risk perception related in general to nanotech applications, but as expected, notably surrounding the food field. Studies carried out to assess the social implications of nanotechnologies indicate that a good regulation is critical for achieving trust and ensuring acceptance of the technology by the consumers. The consumer-safety implications from nanotechnology applications in food are intrinsically linked to the physicochemical nature of the NPs and to the likelihood and extent of exposure through consumption of nanofoods. The nature of hazard and potential consumer's risk from nanotechnology-derived food and food packaging have increasingly been explored in latest years, but there are still wide knowledge gaps that need to be filled before the potential of nanotechnological agri-food applications can be realized.

Presently, all sorts of different structures of interest for nanoscience and nanotechnologies are being designed and prepared in laboratories by assembling a variety of building blocks and varying functionalities. As well known from studies carried out on various nanomaterials, primarily on the wide family of nanocarbons, the functional properties of materials at the nanoscale are driven by shape, size and assembling of moieties in organized structures. Therefore the control of surfaces and of the architectures resulting from induced aggregation or spontaneous selfassembling of the nanocomponents, is the critical step for production of nanofood with pre-defined properties.
A main challenge in the application of nanocomponents in food and food-related fields as well as in their safety assessment is the adequate characterization of the structures in terms of size, shape, uniformity, agglomeration, chemical purity, and stability per se, in the food product and under testing conditions. For the toxicity testing of materials, the use of standards and of validated methods is strongly needed.

Overall, in such a context, it is evident that the applications of nanotechnologies in food, as well as in all the other fields, cannot progress independently of progress in nanometrology, the science of measurement able to define size, mass, force, and functional properties at the nanoscale. The biological impact of ENMs is strictly related to all these properties. Physicochemical properties (as size, coatings and charge, particles clustering and modifications of surface) may influence their cell surface binding and internalization properties, and toxic outcomes.

The lack of an adequate appreciation of the synergistic relation between nanotechnology and nanometrology could hamper the progress of the nanotechnology and/or could significantly increase the time to market for many applications, including particularly those related to the food sector.

\section{References}

Achayuthakan, P., Suphantharika, M., \& BeMiller, J. N. (2012). Confocal laser scanning microscopy of dextranrice starch mixtures. Carbohydrate Polymers, 87, 557-563.

An, H., Yang, H., Liu, Z., \& Zhang, Z. (2008). Effects of heating modes and sources on nanostructure of gelatinized starch molecules using atomic force microscopy. LWT - Food Science Technology, 41, 1466-1471.

Aureli, F., D'Amato, M., De Berardis, B., Raggi, A., Turco, A. C., \& Cubadda, F. (2012). Investigating agglomeration and dissolution of silica nanoparticles in aqueous suspensions by dynamic reaction cell inductively coupled plasma-mass spectrometry in time resolved mode. Journal of Analytical Atomic Spectrometry, 27, 1540-1548.

Baidakova, M. V., Kukushkina, Y. A., Sitnikova, A. A., Yagovkina, M. A., Kirilenko, D. A., Sokolov, V. V., et al. (2013). Structure of nanodiamonds prepared by laser synthesis. Physics of the Solid State, 55, 1747-1753.

Baker, A. A., Miles, M. J., \& Helbert, W. (2001). Internal structure of the starch granule revealed by AFM. Carbohydrate Research, 330, 249-256.

Barber, D. J., \& Freestone, I. C. (1990). An investigation of the origin of the colour of the Lycurgus cup by analytical transmission electron microscopy. Archaeometry, 32, 33-45.

Barrera, G. N., Calderón-Domínguez, G., Chanona-Pérez, J., Gutiérrez-López, G. F., Leóna, A. E., \& Ribotta, P. D. (2013). Evaluation of the mechanical damage on wheat starch granules by SEM, ESEM, AFM and texture image analysis. Carbohydrate Polymers, 98, 1449-1457.

Berquand, A., Gaillard, C., \& Bouchet, B. (2009). Ultrastructure and force property measurements of wheat grain tissues using harmonix mode in fluid. AN122. Bruker Corporation.

Bouwmeester, H., Dekkers, S., Noordam, M. Y., Hagens, W. I., Bulder, A. S., de Heer, C., et al. (2009). Review of health safety aspects of nanotechnologies in food production. Regulatory Toxicology and Pharmacology, 53, 52-62.

Bradley, E. L., Castle, L., \& Chaudhry, Q. (2011). Applications of nanomaterials in food packaging with a consideration of 
opportunities for developing countries. Trends in Food Science \& Technology, 22, 604-610.

Buffat, P., \& Borel, J.-P. (1976). Size effect on the melting temperature of gold particles. Physical Review A, 13, 2287-2298.

Calzolai, L., Gilliland, D., \& Rossi, F. (2012). Measuring nanoparticles size distribution in food and consumer products: a review. Food Additives and Contaminants, 29, 1183-1193.

Celedón, A., \& Aguilera, J. M. (2002). Applications of microprobe Raman spectroscopy in food science. Food Science and Technology International, 8, 101-108.

Chaudhry, Q., Scotter, M., Blackburn, J., Ross, B., Boxall, A., Castle, L., et al. (2008). Applications and implications of nanotechnologies for the food sector. Food Additives \& Contaminants: Part A, 25, 241-258.

Cowley, J. M. (1975). Diffraction physics. Amsterdam: North-Holland.

Cubadda, F., Aureli, F., D'Amato, M., Raggi, A., \& Mantovani, A (2013). Nanomaterials in the food sector: new approaches for safety assessment. Rapporti ISTISAN 13/48.

Cubadda, F., Oomen, A. G., Laurentie, M., Aureli, F., D'Amato, M., Maranghi, F., et al. (2014). Toxicokinetics of synthetic amorphous silica after oral and intravenous administration in rats (in preparation).

Cushen, M., Kerry, J., Morris, M., Cruz-Romero, M., \& Cummins, E. (2012). Nanotechnologies in the food industry - recent developments, risks and regulation. Trends in Food Science \& Technology, 24, 30-46.

Daniel, M.-C., \& Astruc, D. (2004). Gold nanoparticles: assembly, supramolecular chemistry, quantum-size-related properties, and applications toward biology, catalysis, and nanotechnology. Chemical Reviews, 104, 293-346.

Dekkers, S., Krystek, P., Peters, R. J., Lankveld, D. P., Bokkers, B. G., van Hoeven-Arentzen, P. H., et al. (2011). Presence and risks of nanosilica in food products. Nanotoxicology, 5, 393-405.

Dudkiewicz, A., Tiede, K., Loeschner, K., Soegaard Jensen, L. H. Jensen, E., Wierzbicki, R., et al. (2011). Characterization of nanomaterials in food by electron microscopy. Trends in Analytical Chemistry, 30, 28-43.

Dufour, E. (2011). Recent advances in the analysis of dairy product quality using methods based on the interactions of light with matter. International Journal of Dairy Technology, 64, 153-165.

Echegoyen, Y., \& Nerín, C. (2013). Nanoparticle release from nanosilver antimicrobial food containers. Food and Chemical Toxicology, 62, 16-22.

EFSA Scientific Committee. (2009). Scientific opinion of the scientific committee on a request from the european commission on the potential risks arising from nanoscience and nanotechnologies on food and feed safety. The EFSA Journal, 958, 1-39.

EFSA Scientific Committee. (2011). Scientific opinion on guidance on the risk assessment of the application of nanoscience and nanotechnologies in the food and feed chain. The EFSA Journal, 9, 2140-2176.

El-Bakry, M., \& Sheehan, J. (2014). Analysing cheese microstructure: a review of recent developments. Journal of Food Engineering, 125, 84-96.

Fava, J., Hodara, K., Nieto, A., Guerrero, S., Alzamora, S. M., \& Castro, M. A. (2011). Structure (micro, ultra, nano), color and mechanical properties of Vitis labrusca I. (grape berry) fruits treated by hydrogen peroxide, UVC irradiation and ultrasound. Food Research International, 44, 2938-2948.

Fröhlich, E., \& Roblegg, E. (2012). Models for oral uptake of nanoparticles in consumer products. Toxicology, 291, 10-17.

Funami, T. (2010). Atomic force microscopy imaging of food polysaccharides. Food Science and Technology Research, 16, $1-12$.

Fyfe, K. N., Kravchuk, O., Le, T., Deeth, H. C., Nguyen, A. V., \& Bhandari, B. (2011). Storage induced changes to high protein powders: influence on surface properties and solubility. Journal of the Science of Food and Agriculture, 91, 2566-2575.

Gao, G., Ze, Y., Li, B., Zhao, X., Zhang, T., Sheng, L., et al. (2012). Ovarian dysfunction and gene-expressed characteristics of female mice caused by long-term exposure to titanium dioxide nanoparticles. Journal of Hazardous Materials, 243, 19-27.

Gao, G., Ze, Y., Zhao, X., Sang, X., Zheng, L., Ze, X., et al. (2013). Titanium dioxide nanoparticle-induced testicular damage, spermatogenesis suppression, and gene expression alterations in male mice. Journal of Hazardous Materials, 258-259, 133-143.

Gatti, A. M., Tossini, D., Gambarelli, A., Montanari, S., \& Capitani, F. (2009). Investigation of the presence of inorganic micro- and nanosized contaminants in bread and biscuits by environmental scanning electron microscopy. Critical Reviews in Food Science and Nutrition, 49, 275-282.

von Goetz, N., Fabricius, L., Glaus, R., Weitbrecht, V., Günther, D., \& Hungerbühler, K. (2013). Migration of silver from commercial plastic food containers and implications for consumer exposure assessment. Food Additives \& Contaminants: Part A, 30, 612-620.

Goode, K. R., Bowen, J., Akhtar, N., Robbins, P. T., \& Fryer, P. J. (2013). The effect of temperature on adhesion forces between surfaces and model foods containing whey protein and sugar. Journal of Food Engineering, 118, 371-379.

Guglielmotti, V., Chieppa, S., Orlanducci, S., Tamburri, E., Toschi, F., Terranova, M. L., et al. (2009). Carbon nanotube/nanodiamond structures: an innovative concept for stable and ready-to-start electron emitters. Applied Physics Letters, 95, 222113.

Guglielmotti, V., Tamburri, E., Orlanducci, S., Terranova, M. L. Rossi, M., Notarianni, M., et al. (2013). Macroscopic self-standing swcnt fibers as efficient emitters with very high emission current for robust cold cathodes. Carbon, 52, 356-362.

Hadrup, N., Loeschner, K., Bergström, A., Wilcks, A., Gao, X., Vogel, U., et al. (2012). Subacute oral toxicity investigation of nanoparticulate and ionic silver in rats. Archives of Toxicology, $86,543-551$.

Heroult, J., Nischwitz, V., Bartczak, D., \& Goenaga-Infante, H. (2014). The potential of asymmetric flow field-flow fractionation hyphenated to multiple detectors for the quantification and size estimation of silica nanoparticles in a food matrix. Analytical and Bioanalytical Chemistry, 406, 3919-3927.

Herrero, A. M. (2008). Raman spectroscopy a promising technique for quality assessment of meat and fish: a review. Food Chemistry, 107, 1642-1651.

Honglong, S., Guling, Z., Bin, Z., Minting, L., \& Wenzhong, W. (2013). A method for structure analysis of nanomaterials by electron diffraction: phase identification and unit cell determination. Microscopy Research \& Technique, 76, 641-647.

Huang, T., \& Xu, X.-H. N. (2010). Synthesis and characterization of tunable rainbow colored colloidal silver nanoparticles using single-nanoparticle plasmonic microscopy and spectroscopy. Journal of Materials Chemistry, 20, 9867-9876.

Huang, X., \& El-Sayed, M. A. (2010). Gold nanoparticles: optical properties and implementations in cancer diagnosis and photothermal therapy. Journal of Advanced Research, 1, 13-28.

Hunt, L. B. (1976). The true story of purple of Cassius. Gold Bull, 9, $134-139$

lijima, S. (1991). Helical microtubules of graphitic carbon. Nature 354, 56-58.

James, B. (2009). Advances in "wet" electron microscopy techniques and their application to the study of food structure. Trends in Food Science \& Technology, 20, 114-124.

James, B. J., \& Smith, B. G. (2009). Surface structure and composition of fresh and bloomed chocolate analysed using X-ray photoelectron spectroscopy, cryo-scanning electron microscopy and environmental scanning electron microscopy. LWT - Food Science and Technology, 42, 929-937. 
Jun, Y.-W., Seo, J.-W., \& Cheon, J. (2008). Nanoscaling laws of magnetic nanoparticles and their applicabilities in biomedical sciences. Accounts of Chemical Research, 41, 179-189.

Kah, M., \& Hofmann, T. (2014). Nanopesticide research: current trends and future priorities. Environment International, 63, 224-235.

van Kesteren, P. C. E., Cubadda, F., Bouwmeester, H., van Eijkeren, J. C. H., Dekkers, S., de Jong, W. H., et al. (2014). Novel insights into the risk assessment of the nanomaterial synthetic amorphous silica, additive E551, in food. Nanotoxicology, (Epub ahead of print July 18, 2014 - http://dx.doi.org/10.3109/ 17435390.2014.940408).

Kim, Y. S., Kim, J. S., Cho, H. S., Rha, D. S., Kim, J. M., Park, J. D., et al. (2008). Twenty-eight-day oral toxicity, genotoxicity, and gender-related tissue distribution of silver nanoparticles in sprague-dawley rats. Inhalation Toxicology, 20, 575-583.

Kim, Y. S., Song, M. Y., Park, J. D., Song, K. S., Ryu, H. R., Chung, Y. H., et al. (2010). Subchronic oral toxicity of silver nanoparticles. Particle and Fibre Toxicology, 7, 20.

Kookana, R. S., Boxall, A. B. A., Reeves, P. T., Ashauer, R., Beulke, S., Chaudhry, Q., et al. (2014). Nanopesticides: guiding principles for regulatory evaluation of environmental risks. Journal of Agricultural and Food Chemistry, 62, 4227-4240.

Kroto, H. W., Heath, J. R., O'Brien, S. C., Curl, R. F., \& Smalley, R. E. (1985). C60: buckminsterfullerene. Nature, 318, 162-163.

Leach, R. K., Boyd, R., Burke, T., Danzebrink, H. U., Dirscherl, K., Dziomba, T., et al. (2011). The European nanometrology landscape. Nanotechnology, 22, 062001.

Linsinger, T. P., Chaudhry, Q., Dehalu, V., Delahaut, P., Dudkiewicz, A., Grombe, R., et al. (2013). Validation of methods for the detection and quantification of engineered nanoparticles in food. Food Chemistry, 138, 1959-1966.

Linsinger, T. P., Peters, R., \& Weigel, S. (2014). International interlaboratory study for sizing and quantification of ag nanoparticles in food simulants by single-particle icpms. Analytical and Bioanalytical Chemistry, 406, 3835-3843.

Liu, D., \& Cheng, F. (2011). Advances in research on structural characterisation of agricultural products using atomic force microscopy. Journal of the Science of Food and Agriculture, 91, 783-788.

Llorens, A., Lloret, E., Picouet, P. A., Trbojevich, R., \& Fernandez, A. (2012). Metallic-based micro and nanocomposites in food contact materials and active food packaging. Trends in Food Science \& Technology, 24, 19-29.

Loeschner, K., Hadrup, N., Qvortrup, K., Larsen, A., Gao, X., Vogel, U., et al. (2011). Distribution of silver in rats following 28 days of repeated oral exposure to silver nanoparticles or silver acetate. Particle and Fibre Toxicology, 8, 18.

Loeschner, K., Navratilova, J., Købler, C., Mølhave, K., Wagner, S., von der Kammer, F., et al. (2013). Detection and characterization of silver nanoparticles in chicken meat by asymmetric flow field flow fractionation with detection by conventional or single particle icp-ms. Analytical and Bioanalytical Chemistry, 405, 8185-8195.

Lue, J. T. (2007). Physical properties of nanomaterials. In H. S. Nalwa (Ed.). Encyclopedia of nanoscience and nanotechnology, (Vol. X pp. 1-46).

Mochalin, V. N., S, O., Ho, D., \& Gogotsi, Y. (2012). The properties and applications of nanodiamonds. Nature Nanotechnology, 7, $11-23$.

Morales, M. P., Veintemillas-Verdaguer, S., Montero, M. I., Serna, C. J., Roig, A., Casas, L., et al. (1999). Surface and internal spin canting in $\gamma-\mathrm{Fe}_{2} \mathrm{O}_{3}$ nanoparticles. Chemistry of Materials, 11, 3058-3064.

Morris, V. J. (2004). Probing molecular interactions in food. Trends in Food Science \& Technology, 15, 291-297.

Morris, V. J. (2011). Emerging roles of engineered nanomaterials in the food industry. Trends in Biotechnology, 29, 509-516.
Morris, V. J., Woodward, N. C., \& Gunning, A. P. (2011). Atomic force microscopy as a nanoscience tool in rational food design. Journal of the Science of Food and Agriculture, 91, 2117-2125.

Morton, D. N., Roberts, C. J., Hey, M. J., Mitchell, J. R., Hipkiss, J., \& Vercauteren, J. (2003). Surface characterization of caramel at the micrometer scale. Journal of Food Science, 68, $1411-1415$.

Neethirajan, S., Tsukamoto, K., Kanahara, H., \& Sugiyama, S. (2012). Ultrastructural analysis of buckwheat starch components using atomic force microscopy. Journal of Food Science, 71, N2-N7.

Ong, L., Dagastine, R. R., Kentish, S. E., \& Gras, S. L. (2011). Microstructure of milk gel and cheese curd observed using cryo scanning electron microscopy and confocal microscopy. LWT Food Science Technology, 44, 1291-1302.

Park, E.-J., Bae, E., Yi, J., Kim, Y., Choi, K., Lee, S. H., et al. (2010). Repeated-dose toxicity and inflammatory responses in mice by oral administration of silver nanoparticles. Environmental Toxicology and Pharmacology, 30, 162-168.

Passeri, D., Rossi, M., Tamburri, E., \& Terranova, M. L. (2013). Mechanical characterization of polymeric thin films by atomic force microscopy based techniques. Analytical and Bioanalytical Chemistry, 405, 1463-1478.

Peighambardoust, S. H., Dadpour, M. R., \& Dokouhaki, M. (2010). Application of epifluorescence light microscopy (EFLM) to study the microstructure of wheat dough: a comparison with confocal scanning laser microscopy (CSLM) technique. Journal of Cereal Science, 51, 21-27.

Peters, R., ten Dam, G., Bouwmeester, H., Helspera, H., Allmaier, G. vd Kammer, F., et al. (2011). Identification and characterization of organic nanoparticles in food. Trends in Analytical Chemistry, 30, $100-112$.

Peters, R., Kramer, E., Oomen, A. G., Rivera, Z. E., Oegema, G., Tromp, P. C., et al. (2012). Presence of nano-sized silica during in vitro digestion of foods containing silica as a food additive. ACS Nano, 6, 2441-2451.

Peters, R. J., Rivera, Z. H., van Bemmel, G., Marvin, H. J., Weigel, S., \& Bouwmeester, H. (2014). Development and validation of single particle icp-ms for sizing and quantitative determination of nanosilver in chicken meat. Analytical and Bioanalytical Chemistry, 406, 3875-3885.

Reibold, M., Paufler, P., Levin, A. A., Kochmann, W., Pätzke, N., \& Meyer, D. C. (2006). Carbon nanotubes in an ancient Damascus sabre. Nature, 444, 286.

Ridout, M. J., Gunning, A. P., Parker, M. L., Wilson, R. H., \& Morris, V. J. (2002). Using AFM to image the internal structure of starch granules. Carbohydrate Polymers, 50, 123-132.

Ridout, M. J., Parker, M. L., Hedley, C. L., Bogracheva, T. Y., \& Morris, V. J. (2003). Atomic force microscopy of pea starch granules: granule architecture of wild-type parent, $r$ and $r b$ single mutants, and the rrb double mutant. Carbohydrate Research, 338, $2135-2147$.

Ridout, M. J., Parker, M. L., Hedley, C. L., Bogracheva, T. Y., \& Morris, V. J. (2006). Atomic force microscopy of pea starch: granule architecture of the rug3-a, rug4-b, rug5-a and lam-c mutants. Carbohydrate Polymers, 65, 64-74.

Roduner, E. (2006). Size matters: why nanomaterials are different. Chemical Society Reviews, 35, 583-592.

Roebben, G., Rasmussen, K., Kestens, V., Linsinger, T. P. J., Rauscher, H., Emons, H., et al. (2013). Reference materials and representative test materials: the nanotechnology case. Journal of Nanoparticle Research, 15, 1-13.

Rösler, J., Bäker, M., \& Harders, H. (2007). Mechanical behaviour of engineering materials. Berlin Heidelberg: Springer.

Rossi, M., Manno, D., Orlanducci, S., Serra, A., \& Terranova, M. L. (2011). Electron diffraction analysis of carbon-based nanomaterials. In H. S. Nalwa (Ed.). Encyclopedia of nanoscience and nanotechnology, (Vol. 13 pp. 375-425). 
Sahin, O., \& Erina, N. (2008). High-resolution and large dynamic range nanomechanical mapping in tapping-mode atomic force microscopy. Nanotechnology, 19, 445717.

Sahin, O., Magonov, S., Su, C., Quate, C. F., \& Solgaard, O. (2007). An atomic force microscope tip designed to measure time-varying nanomechanical forces. Nature Nanotechnology, 2, 507-514.

Sang, X., Zheng, L., Sun, Q., Li, N., Cui, Y., Hu, R., et al. (2012). The chronic spleen injury of mice following long-term exposure to titanium dioxide nanoparticles. Journal of Biomedical Materials Research Part A, 100, 894-902.

Schmidt, B., Petersen, J. H., Bender Koch, C., Plackett, D., Johansen, N. R., Katiyar, V., et al. (2009). Combining asymmetrical flow field-flow fractionation with light-scattering and inductively coupled plasma mass spectrometric detection for characterization of nanoclay used in biopolymer nanocomposites. Food Additives and Contaminants, 26, 1619-1627.

Schwirn, K., Tietjen, L., \& Beer, I. (2014). Why are nanomaterials different and how can they be appropriately regulated under REACH? Environmental Sciences Europe, 26, 4.

Scramin, J. A., de Britto, D., Forato, L. A., Bernardes-Filho, R., Colnago, L. A., \& Assis, O. B. G. (2011). Characterisation of zeinoleic acid films and applications in fruit coating. International Journal of Food Science \& Technology, 46, 2145-2152.

Serra, A., Manno, D., Filippo, E., Tepore, A., Terranova, M. L., Orlanducci, S., et al. (2008). Photoconductivity of packed homotype bundles formed by aligned single-walled carbon nanotubes. Nano Letters, 8, 968-971.

Sharma, V., Park, K., \& Srinivasarao, M. (2009). Colloidal dispersion of gold nanorods: historical background, optical properties, seedmediated synthesis, shape separation and self-assembly. Materials Science \& Engineering $R, 65,1-38$.

Sheen, S., Bao, G., \& Cooke, P. (2008). Food surface texture measurement using reflective confocal laser scanning microscopy. Journal of Food Science, 73, E227-E234.

Shenderova, O. A., \& Gruen, D. M. (Eds.), (2012). Ultrananocrystalline diamond: Synthesis, properties, and applications. Elsevier.

Silvestre, C., Duraccio, D., \& Cimmino, S. (2011). Food packaging based on polymer nanomaterials. Progress in Polymer Science, 36, $1766-1782$.

Tamburri, E., Guglielmotti, V., Matassa, R., Orlanducci, S., Gay, S. Reina, G., et al. (2014). Detonation nanodiamonds taylor the structural order of PEDOT chains in conductive coating layers of hybrid nanoparticles. Journal of Materials Chemistry C, 2, 3703-3716.

Tao, Y., Endo, M., \& Kaneko, K. (2012). Recent progress on the synthesis and applications of carbon nanotubes. In X. Fang, \& L. Wu (Eds.), Handbook of innovative nanomaterials: From syntheses to applications (pp. 639-663).

Tassinari, R., Cubadda, F., Moracci, G., Aureli, F., D'Amato, M., Valeri, M., et al. (2014). Oral, short-term exposure to titanium dioxide nanoparticles in Sprague-Dawley rat: focus on reproductive and endocrine systems and spleen. Nanotoxicology, 8, 654-662.

Tatham, A. S., Thomson, N. H., McMaster, T. J., Humphris, A. D. L., Miles, M. J., \& Shewry, P. R. (1999). Scanning probe microscopy studies of cereal seed storage protein structures. Scanning, 21 , $293-298$

Terranova, M. L., Manno, D., Rossi, M., Serra, A., Filippo, E., Orlanducci, S., et al. (2009). New developments in transmission electron microscopy for nanotechnology. Crystal Growth \& Design, 9, 1245-1249.

Terranova, M. L., Sessa, V., \& Rossi, M. (2006). The world of carbon nanotubes: an overview of CVD growth methodologies. Chemical Vapor Deposition, 12, 315-325.
Tiede, K., Boxall, A. B., Tear, S. P., Lewis, J., David, H., \& Hassellov, M. (2008). Detection and characterization of engineered nanoparticles in food and the environment. Food Additives \& Contaminants: Part A, 25, 795-821.

Tinkle, S., McNeil, S. E., Mühlebach, S., Bawa, R., Borchard, G. Barenholz, Y., et al. (2014). Nanomedicines: addressing the scientific and regulatory gap. Annals of the New York Academy of Sciences, 1313, 35-56.

Urban, K. W. (2011). Electron microscopy: the challenges of graphene. Nature Materials, 10, 165-166.

van de Velde, F., van Riel, J., \& Tromp, R. H. (2002). Visualisation of starch granule morphologies using confocal scanning laser microscopy (CSLM). Journal of the Science of Food and Agriculture, 82, 1528-1536.

Venema, L. C., Wildöer, J. W. G., Dekker, C., Rinzler, G. A., \& Smalley, R. E. (1998). STM atomic resolution images of single-wall carbon nanotubes. Applied Physics A, 66, S153-S155.

Wagner, F. E., Haslbeck, S., Stievano, L., Calogero, S., Pankhurst, Q. A., \& Martinek, K.-P. (2000). Before striking gold in gold-ruby glass. Nature, 407, 691-692.

Warner, J. H., Young, N. P., Kirkland, A. I., \& Briggs, G. A. D. (2011) Resolving strain in carbon nanotubes at the atomic level. Nature Materials, 10, 958-962.

Weiss, J., Takhistov, P., \& McClements, D. J. (2006). Functional materials in food nanotechnology. Journal of Food Science, 71, R107-R116.

Williams, O. A., Douhéret, O., Daenen, M., Haenen, K., Ōsawa, E., \& Takahashi, M. (2007). Enhanced diamond nucleation on monodispersed nanocrystalline diamond. Chemical Physics Letters, 445, 255-258.

Yang, D., \& Ying, Y. (2011). Applications of raman spectroscopy in agricultural products and food analysis: a review. Applied Spectroscopy Reviews, 46, 539-560.

Yang, H., Wang, Y., Lai, S., An, H., Li, Y., \& Chen, F. (2007). Application of atomic force microscopy as a nanotechnology tool in food science. Journal of Food Science, 72, R65-R75.

Yang, Y., Rigdon, W., Huang, X., \& Li, X. (2013). Enhancing graphene reinforcing potential in composites by hydrogen passivation induced dispersion. Scientific Reports, 3, 2086.

Zaman, I., Manshoor, B., Khalid, A., \& Araby, S. (2014). From clay to graphene for polymer nanocomposites-a survey. Journal of Polymer Research, 21, 429.

Zan, R., Ramasse, Q. M., Jalil, R., \& Bangert, U. (2013). Atomic structure of graphene and h-BN layers and their interactions with metals. In M. Aliofkhazraei (Ed.), Advances in graphene science (pp. 639-663).

van der Zande, M., Vandebriel, R. J., Groot, M. J., E., K., Herrera Rivera, Z. E., Rasmussen, K., Ossenkoppele, J. S., et al. (2014). Sub-chronic toxicity study in rats orally exposed to nanostructured silica. Particle and Fibre Toxicology, 11, 8.

van der Zande, M., Vandebriel, R. J., Van Doren, E., Kramer, E., Herrera Rivera, Z., Serrano-Rojero, C. S., et al. (2012). Distribution, elimination, and toxicity of silver nanoparticles and silver ions in rats after 28-day oral exposure. ACS Nano, 28, $7427-7442$.

Zdunek, A., \& Kurenda, A. (2013). Determination of the elastic properties of tomato fruit cells with an atomic force microscope. Sensors, 13, 12175-12191.

Zhang, J., Cui, J., Xiao, L., \& Wang, Z. (2014). The combination of atomic force microscopy and sugar analysis to evaluate alkali-soluble Canna edulis Ker pectin. Food Chemistry, 156, $64-71$.

Zhao, X., Ze, Y., Gao, G., Sang, X., Li, B., Gui, S., et al. (2013). Nanosized $\mathrm{TiO}_{2}$-induced reproductive system dysfunction and its mechanism in female mice. PLoS One, 8, e59378. 